UCRL-ID-141614

\title{
New Millennium Program - Space Technology 6 (ST6)
}

R. Hyde, C. Satter, R. Hoyt, J. Early, S. Dixit, A. Weisberg, M. Shao, R. Baron

\section{November 21, 2000}

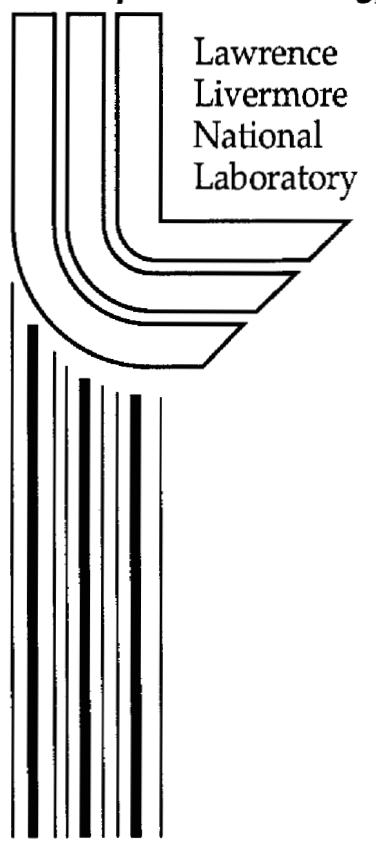




\section{DISCLAIMER}

This document was prepared as an account of work sponsored by an agency of the United States Government. Neither the United States Government nor the University of California nor any of their employees, makes any warranty, express or implied, or assumes any legal liability or responsibility for the accuracy, completeness, or usefulness of any information, apparatus, product, or process disclosed, or represents that its use would not infringe privately owned rights. Reference herein to any specific commercial product, process, or service by trade name, trademark, manufacturer, or otherwise, does not necessarily constitute or imply its endorsement, recommendation, or favoring by the United States Government or the University of California. The views and opinions of authors expressed herein do not necessarily state or reflect those of the United States Government or the University of California, and shall not be used for advertising or product endorsement purposes.

This work was performed under the auspices of the U. S. Department of Energy by the University of California, Lawrence Livermore National Laboratory under Contract No. W-7405-Eng-48.

This report has been reproduced directly from the best available copy.

Available electronically at http://www.doc.gov/bridge

Available for a processing fee to U.S. Department of Energy

And its contractors in paper from

U.S. Department of Energy

Office of Scientific and Technical Information

P.O. Box 62

Oak Ridge, TN 37831-0062

Telephone: (865) 576-8401

Facsimile: (865) 576-5728

E-mail: reports@adonis.osti.gov

Available for the sale to the public from

U.S. Department of Commerce

National Technical Information Service

5285 Port Royal Road

Springfield, VA 22161

Telephone: (800) 553-6847

Facsimile: (703) 605-6900

E-mail: orders@ntis.fedworld.gov

Online ordering: http://www.ntis.gov/ordering.htm

OR

Lawrence Livermore National Laboratory

Technical Information Department's Digital Library

http:/ / www.llnl.gov/tid/Library.html 
New Millennium Program - Space Technology 6 (ST6)

November 21, 2000

Folded Optical Lens Deployment (FOLD) Demonstration of a 1.5 - 2.4 meter Lightweight Diffractive Optic

Technology Capability: A.4 Membrane Optics Deployment

Institution: Lawrence Livermore National Laboratory

Laser Science \& Technology Program

Business contact:

Kathy Allen, L-482

LLNL

P.O.Box 808

Livermore, CA 94550

925-423-4009(phone)

925-422-5537(FAX)

allen7@IInl.gov

Proposing Technology Provider:

Roderick Hyde, L-477

LLNL

P.O.Box 808,

Livermore, CA 94550

925-422-7289(phone)

925-422-5537(FAX)

hyde1@IInl.gov

Institutional Authorization

Lloyd A. Hackel

Program Leader,

Laser Science \& Technology Program

Lawrence Livermore National Laboratory

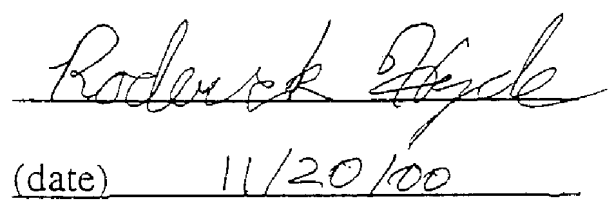

(date)

Type of Proposing Institution: FFRDC operated on non-profit basis by the University of California

Proposed Funding: Study Phase - \$350k 


\section{Proposal Summary}

In order to view exo-solar planets and to improve our knowledge of the early universe, it is important to field very large, 100-meter-class, space telescopes. To be able to practically and affordably field such instruments, it is essential to develop membrane optics that are both lighter and more compactly packagable than present space optics.

We will demonstrate a significant breakthrough in membrane optics utilizing thin diffractive lenses instead of reflective films. The uniqueness of this approach is that diffractive lenses utilize globally-flat, easily supported, membranes, and are many orders-of-magnitude less sensitive to out-of-plane surface errors than are reflective optics.

Our flight-validation experiment will launch, deploy, and optically test a lightweight diffractive lens. This lens will be built from multiple thin glass sheets, each optically patterned as a diffractive lens panel and then joined together to form a multi-segment foldable lens. The folded-up lens is tightly packaged to survive launch loads and supported after deployment by an outer rim. Its optical PSF performance is then measured by using a three-conponent system consisting of the diffractive lens, linked by tethers to an optical-beacon on one side, and a sensorpod on the other.

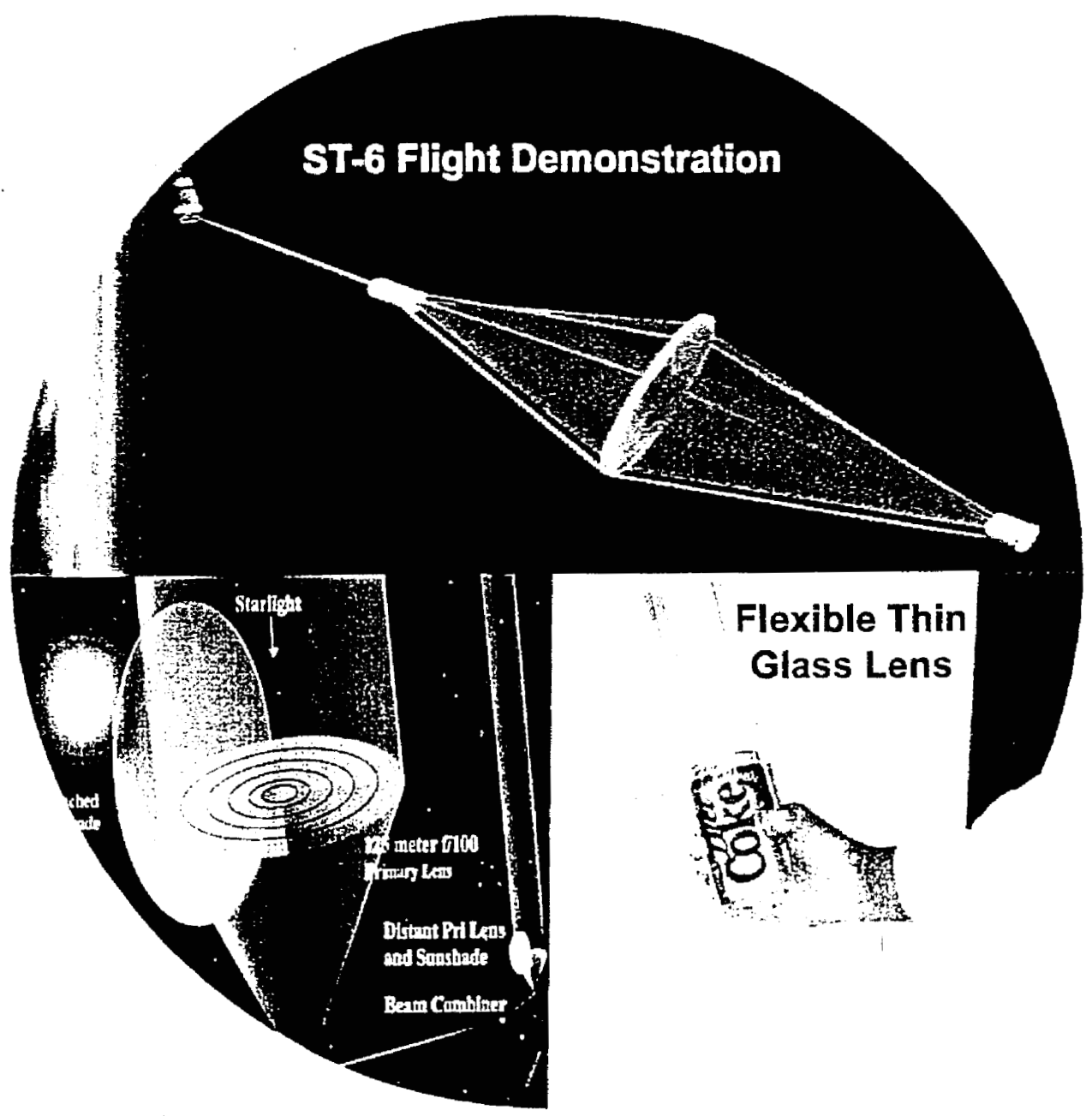




\section{Table of Contents}

\section{Cover Page}

Table of Contents

Technical/ Management Section

Technical merit based on requirements

Expected capability enhancement

Diffractive lenses for membrane optics

Technology development challenges

Rationales for space flight validation

Validation approach and experiment objectives

Status of development and TRL basis

Approach to TRL 4 in study phase

End-to-end development plan through flight validation

Risk mitigation procedures

Team capabilities and past performance

Project organization and study phase management

References

Facilities and Equipment

Current and Pending Support

Weisberg 34

Shao $\quad 35$

Baron 36 


\section{Technical Approach}

\section{Summary Description of the Proposed Technology and Concept for Flight Validation}

We will demonstrate a significant breakthrough in membrane optics utilizing thin diffractive lenses instead of reflective films. The uniqueness of this approach is that diffractive lenses utilize globally-flat, easily supported, membranes, and are many orders-of-magnitude less sensitive to out-of-plane surface ripples than are reflective optics.

Our flight-validation experiment will launch, deploy, and optically test a lightweight diffractive lens. This lens will be built from multiple thin glass sheets, each optically patterned as a diffractive lens panel and then joined together to form a multi-segment foldable lens. The folded-up lens is tightly packaged to survive launch loads and supported after deployment by an outer rim. Its optical PSF performance is then measured by using a three-component system consisting of the diffractive lens, linked by tethers to an optical-beacon on one side, and a sensor-pod on the other

Technical merit as applied to Technology Needs and Validation Requirements

\begin{tabular}{|l|ccc|}
\hline Technology Validation Needs & $\begin{array}{l}\text { Proposed Space } \\
\text { Demonstration }\end{array}$ & $\begin{array}{l}\text { NMP Validation } \\
\text { Requirements }\end{array}$ & $\begin{array}{l}\text { Technology } \\
\text { Potential }\end{array}$ \\
\hline Optic diameter (meters) & $1.5-2.4$ & $>0.5$ & $>100$ \\
Areal density of membrane $\left(\mathrm{kg} / \mathrm{m}^{2}\right)$ & 1.0 & $\sim 1$. & $\sim 0.1$ \\
Deployed surface accuracy $(\lambda)$ & $\sim 1$ & $<200$ & 0.1 \\
\hline
\end{tabular}

\section{Expected capability enhancement to achieve benefits to future science missions}

Once this technology is flight demonstrated, its deployment in operational space telescopes will have a revolutionary impact on astronomy. In order to view exo-solar planets and to improve our knowledge of the early universe, it is important to field large, 25-150 meter, aperture space telescopes. Such telescopes are, of course, very much larger than either Hubble, or the planned NGST. To be able to practically and affordably field such instruments, it is essential to develop optical apertures that are both lighter and more compactly packagable than present space optics. Membrane optics, based upon the use of thin, lightweight, films of material offer the promise of achieving these goals, thereby permitting the future fielding of very large aperture space telescopes.

\section{Diffractive Lenses for Membrane Optics: The Approach and its Advantages}

There is considerable interest and effort in developing membrane mirrors. These basically offer a way to drastically reduce the weight of current, reflector-based space telescopes; replacing thick, rigid, reflective surfaces with thin, flexible ones. The challenge here is achieving tight optical tolerances while using thin membranes instead of thick, rigid substrates. A number of approaches to doing so, combining various levels of passive shape tolerances, active figure control, and adaptive optics are being explored by researchers in this area.

We will investigate an alternative approach to membrane optics, based on lenses rather than mirrors. While this approach will incur its own set of challenges, it does offer significant space-fielding and optical-tolerance advantages over the more conventional membrane mirror approach. 


\section{EYEGLASS Space Telescope}

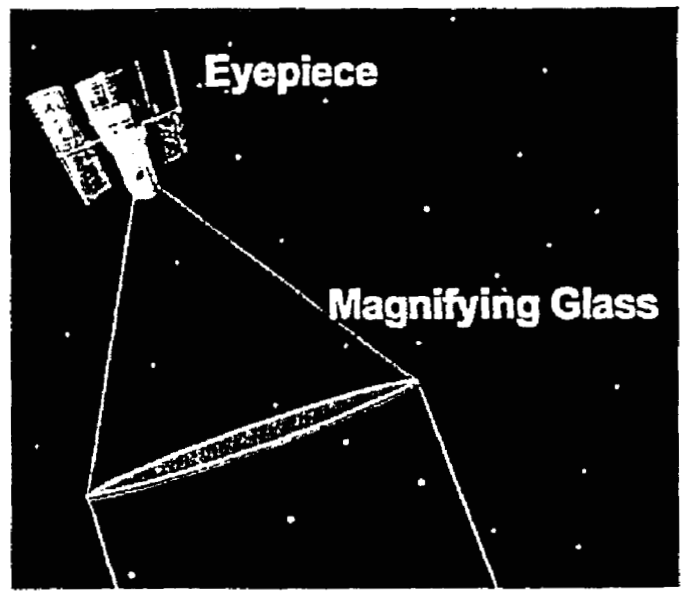

A diffractive space telescope (Eyeglass) consists of two distinct spacecraft, separated in space by a few kilometers. The telescope's large aperture is provided by a transmissive diffractive lens, acting as a Magnifying Glass. This large lens gathers and gently focuses light, directing it to a distant focal surface, where it is collected by a separate, much smaller, space telescope serving as the Eyeglass's mobile Eyepiece.

Fielding a large diffractive space telescope involves not just the large aperture lens, but also the imaging Eyepiece and the cooperative stationkeeping between these two vehicles. While these are important and have been studied before[1], the focus of this proposal is upon the diffractive lens, as it is the key new technology for this membrane optics concept.

The tolerance advantage of lenses stems from the fact that mirrors reflect light, thereby doubling the effect of surface errors; in contrast, pathlength errors for a thin transmissive film are cancelled, not reinforced. When bending light through an angle $\theta$, lenses bave a $(1+\cos \theta) /(1-\cos \theta)$ tolerance advantage over mirrors. By making the lens weak, i.e., by keeping $\theta$ small, this tolerance gain becomes large, scaling as $4 / \theta^{2}$, i.e., as $16(\mathrm{f} / \#)^{2}$. An optically slow, $f / 100$ lens can tolerate 160,000 times greater shape errors than a similar mirror. This relaxes surface figure tolerance requirements from hundreds of angstroms up to near-cm levels, an enormous practical advantage when trying to field a lightweight, flexible optical element in space.

In order to field a lightweight, membrane-like, aperture, a thin diffractive lens is used instead of a thick refractive one. Diffractive optics (i.e., coherent Fresnel lenses), provide a means to field thin lenses, since they apply the phase profile in a series of discrete, one-wave-deep, phase steps, not a continuous, many-waves-thick profile. This multi-step pattern is physically applied by a series of quadratically-blazed cuts in the surface of a transparent membrane. Since the necessary cuts are shallow (about $1 \mu \mathrm{m}$ deep for a visible system and about $20 \mu \mathrm{m}$ for a thermal-IR one), then a diffractive lens can be quite thin (10 - 100 $\mu \mathrm{m})$ and hence lightweight.

Another space-fielding advantage of diffractive lenses, is that their optical power comes from a surface phase profile, not their shape. This enables us to build lenses from simple flat membranes, having neither local nor global curvature. Such flat membranes are both easier to package for launch and easier to hold in shape after deployment than are the curved films generally used for membrane mirrors.

A diffractive lens therefore offers an attractive way to provide large optical apertures in space: Because it is an optically-slow lens, the traditional, very tight, surface tolerances faced by conventional apertures are virtually eliminated. Because it is a thin, flat, membrane, it is inherently quite fieldable (lightweight, packagable, and easy to hold-in-shape).

\section{Identification of the significant technology development challenges to be overcome}

In order to successfully field large diffractive lenses in space, there are several problems to overcome. The challenges which are unique to this approach involve chromatic aberrations, material transparency, in-plane dimensional tolerances, and diffractive-lens fabrication. 
Folded Optical Lens Deployment (FOLD) Demonstration Of a $1.5-2.4$ meter Lightweight Diffractive Optic

\begin{tabular}{|l|l|l|l|}
\hline Technology challenge & Proposed solution & $\begin{array}{l}\text { Technology development } \\
\text { and ground-based } \\
\text { validation approach }\end{array}$ & Flight validation activity \\
\hline $\begin{array}{l}\text { In-plane dimensional } \\
\text { tolerances }\end{array}$ & $\begin{array}{l}\text { Maintain precision } \\
\text { during lens } \\
\text { fabrication. } \\
\text { Insure adequate } \\
\text { thermal uniformity } \\
\text { in space. }\end{array}$ & $\begin{array}{l}\text { Patterning accuracy in-hand. } \\
\text { Develop precision alignment } \\
\text { and joints. Verify with } \\
\text { metrology. } \\
\text { FEA analysis of in-space } \\
\text { thermal distortions. }\end{array}$ & $\begin{array}{l}\text { Test PSF to determine optical } \\
\text { performance. } \\
\text { Thermal mapping of deployed } \\
\text { lens. }\end{array}$ \\
\hline $\begin{array}{l}\text { Lens deployment and } \\
\text { support }\end{array}$ & $\begin{array}{l}\text { Deployable outer } \\
\text { rim }\end{array}$ & $\begin{array}{l}\text { Design and ground-test the } \\
\text { lens/rim assembly }\end{array}$ & $\begin{array}{l}\text { Carryout actual launch and } \\
\text { deployment. } \\
\text { Image the lens during } \\
\text { deployment. }\end{array}$ \\
\hline $\begin{array}{l}\text { Material transparency } \\
\text { and stability in space }\end{array}$ & Use of glass & $\begin{array}{l}\text { Demonstrate diffractive } \\
\text { patterning of thin glass } \\
\text { sheets }\end{array}$ & $\begin{array}{l}\text { Space stability of glass has } \\
\text { already been demonstrated }\end{array}$ \\
\hline $\begin{array}{l}\text { Brittleness of glass } \\
\text { during launch and } \\
\text { deployment }\end{array}$ & $\begin{array}{l}\text { Dense-packing, } \\
\text { with packing } \\
\text { material between } \\
\text { glass layers }\end{array}$ & $\begin{array}{l}\text { Cross-country postal } \\
\text { shipping demonstrated. } \\
\text { Preflight shake tests of } \\
\text { packaged lens. }\end{array}$ & $\begin{array}{l}\text { Carryout actual launch and } \\
\text { deployment. } \\
\text { Image the lens during } \\
\text { deployment. }\end{array}$ \\
\hline $\begin{array}{l}\text { Chromatic aberration of } \\
\text { diffractive optics }\end{array}$ & $\begin{array}{l}\text { Schupmann } \\
\text { correction via } \\
\text { image collection } \\
\text { optics }\end{array}$ & $\begin{array}{l}\text { Ground demonstration of } \\
\text { broadband diffractive } \\
\text { telescopes }\end{array}$ & $\begin{array}{l}\text { Not necessary; ground } \\
\text { demonstration adequate }\end{array}$ \\
\hline $\begin{array}{l}\text { Diffractive lens } \\
\text { fabrication }\end{array}$ & $\begin{array}{l}\text { Lithographic } \\
\text { patterning of lens } \\
\text { panels. } \\
\text { Assemble lens by } \\
\text { aligning and joining } \\
\text { lens panels. }\end{array}$ & $\begin{array}{l}\text { Fabrication and test of } \\
\text { individual lens panels. } \\
\text { Optical test of assembled } \\
\text { lens. }\end{array}$ & $\begin{array}{l}\text { Not applicable; ground validation } \\
\text { adequate. }\end{array}$ \\
\hline
\end{tabular}

While slow diffractive lenses greatly relax the out-of-plane dimensional tolerances facing membrane optics, they do introduce a new, in-plane tolerance requirement. In order to maintain optical coherence, the "rings" making up the lens's diffractive profile must be in the right radial location. For a visible-band lens, this in-plane tolerance is about $10 \mu \mathrm{ms}$, compared to an out-of-plane value of about $4 \mathrm{~mm}$. These optical tolerances, tight in-plane and loose out-of-plane, are (unlike the case for membrane mirrors) well matched to the natural characteristics of structural membranes, which, once tensioned, are relatively stiff in-plane and floppy out-of-plane.

Obviously, a lens material must be transparent; furthermore, this must be true not just upon deployment, but after prolonged exposure to the space environment as well. This requirement certainly does eliminate some material options, but (depending upon the spectral region of interest) many viable candidates do remain. For instance, lenses operating in the visible and near-infrared region can utilize materials such as silica, glass, polyimides, teflon, etc. If inorganic materials such as glass or silica are used then their brittleness poses significant packaging, launch and deployment challenges.

Diffractive optics are strongly chromatic, the focal length of a lens being directly proportional to frequency. As a result, such optics are generally used for monochromatic (laser) applications', but not the broadband imaging necessary for a space telescope. This problem can be eliminated[2], however, by Schupmann correction, using a second small diffractive element to compensate for the effects of the large primary lens. Using this technique, we have successfully designed, built, and demonstrated, highprecision, broad-band, diffractive telescopes[1]. 
The challenge to actually building a large diffractive lens is evident from comparing the current stateof-the-art $(\sim 50 \mathrm{~cm})$ with desired sizes of $25-150$ meters. Not only is a huge size scale-up required, but the large lenses must be built from thin, foldable, space-suitable materials, not from standard optical ones (cm-thick silica).

One factor mitigating these difficulties is that the required diffractive surface-features are actually fairly large; features for a visible-light $f / 100$ lens are $>100 \mu \mathrm{m}$ everywhere. Given current material patterning practices, the challenge comes from global issues (the large number of features and placement accuracy required), not the local act of creating $100 \mu \mathrm{m}$ surface features. These global challenges can be mitigated by building and assembling the lens out of seamed-together segments, rather than as an all-up, monolithic, structure.

\section{Rationales for space flight validation and justification for validation approach}

While lightweight diffractive lenses have been built and tested on the ground, they have yet to be flown or operated in space. Flight validation is necessary for several reasons: The first is to demonstrate that in-plane dimensional tolerances (the most challenging ones for diffractive lenses) can be maintained in the presence of the thermal environment faced in space. Another concern is, of course, to demonstrate that one can launch and deploy a thin diffractive lens; since we plan to build the lens from thin glass sheets, we need to demonstrate launch-survival as well as precision-deployment. As with all new technologies, a final reason for flight validation is programmatic; it is important to actually fly and demonstrate a new technology to overcome the "never-been-done-yet" barrier to operational use.

\section{Proposed approach for flight validation and specific validation experiment objectives}

We will build a diffractive lens out of a number of joined-together glass panels. This lens is then folded along the joints into a compact package and launched into space. Once there, it is deployed and held taut by a rigid outer rim. The optical performance of the lens will be characterized by PSF (point spread function) measurements, taken by imaging either stars or a beacon onto a CCD camera.

One can build thin diffractive lenses out of either inorganic materials (such as glass or silica) or organic polymers (such as polyimides). Generically the inorganics have the advantage of better dimensional and physical stability in space, while the organics are easier to form and handle as thin films. For this flight experiment we have chosen to baseline glass rather than polymers. The reasons are practical; glass is known to be space stable, moderately thin $(50-1100 \mu \mathrm{m})$ glass microsheets are commercially available, and our group at LLNL already has experience in optically patterning it. LLNL is developing transparent, low CTE, polyimides which offer weight and packaging advantages for diffractive lenses, but they are not ready for this near-term mission.

The Diffractive Optics Group at LLNL has the ability to form thin-glass diffractive lenses at monolithic sizes up to $50-80 \mathrm{~cm}$. Larger sizes can be assembled by joining together multiple panels (we are currently engaged in a program to build a 5 meter lens). The size chosen for this flight validation experiment was influenced more by TRL status, and overall launch, cost and risk issues, than by fabricational capability. Our baseline is currently 1.5 meters as a compromise between what can be made, and what can be reliably flown, deployed, and tested; sizes up to 2.4 meters appear quite buildable and will be considered during the Study phase. 
The thickness of the glass panels (and hence the areal density of the lens) involves a tradeoff between weight and handlability. One can buy large sheets of very thin $(50 \mu \mathrm{m})$ glass, and, when carefully handled, they are quite flexible. This is illustrated in the montage on the Project Summary page showing a tightly rolled $75 \mu \mathrm{m}$ glass sheet. Since, however, in this first flight test, "careful-handling" can't be guaranteed, we will baseline thicker, $400 \mu \mathrm{m}$ sheets, just meeting the validation areal density targets.

Because packagability is crucial to future, large-scale, optics, we believe it is crucial that this flight demonstrate a deployable lens, not a monolithic one. The specific folding pattern will be chosen during the Study Phase. Below we show 3 different folding patterns; the left-most one is the pattern planned for the 5 meter lens we're building for a related project, while the other 2 are simpler patterns under consideration for ST-6.
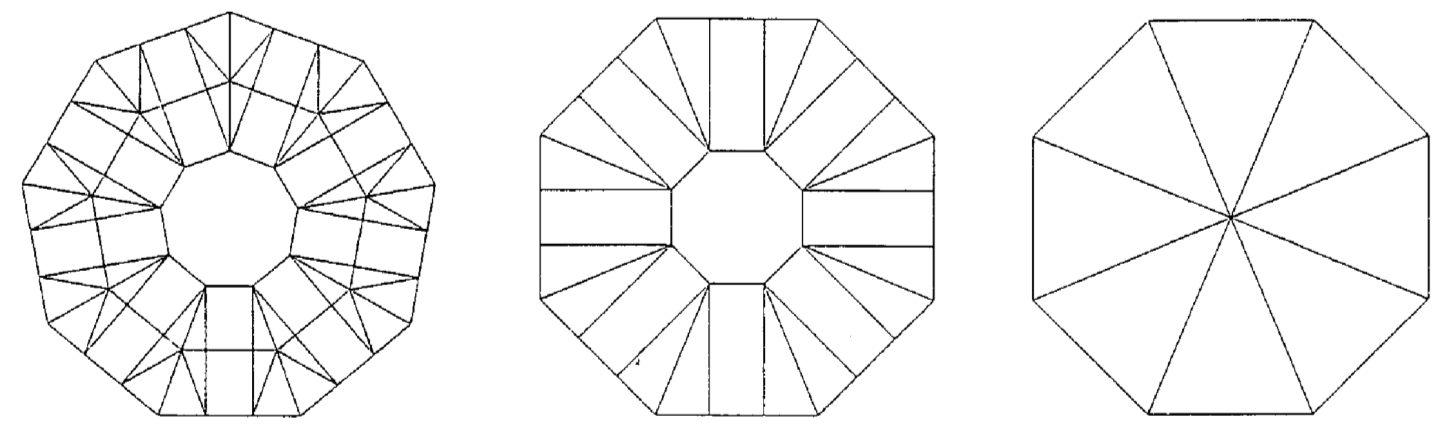

Both the 2 patterns under consideration here offer advantages: The middle pattern folds into a "hatbox", uses smaller panels and offers (via multiple radial rings, as in the left-most pattern) a better approach for folding full-scale lenses. The rightmost pattern folds into a "pizza-stack" delivering a tight, flat package, assembled from identical panels.

One of the challenges to using a glass lens, is its brittleness; unless the lens is well packaged, it will not survive launch. Dense-packs, where glass panels are tightly constrained to prevent motion, are a promising approach to launch-packaging. Under the Advanced Photovoltaic Solar Array (APSA) Program [3], 62 micron solar cells bonded to 50 micron covers, were shown to successfully survive launch vibration and acoustic loads during ground tests when packaged in a lightly compressed package with foam material between the layers. Launch is, however, clearly a risk factor and survivability will be demonstrated by shake-testing early in the effort.

Once delivered to space, the lens must be unfolded and held flat for testing. For this flight-validation experiment we will focus upon a simple system, in which the lens is held in shape via a deployable outer rim. This rim-support approach is scalable for the future (sun shielded) astronomical telescopes of primary interest for astronomy and NASA and will still be adequate for this flight experiment (where the lens will not be sun shielded).

Since the rim must fold-for-launch (just as the lens) we have designed the rim to contain hinged sections, pre-attached to the perimeter of the lens. After unfolding along with the lens, the rim sections are locked together and put in compression, tensioning the lens. The rim compression loads can be imposed either mechanically (by having the rim-segments push against each other) or thermally (given that the mechanical rim segments will be hotter than the transparent glass lens).

The remaining task of the flight-validation experiment is to test the deployed lens, demonstrating that it has an optical quality of $<200 \lambda$. This level of accuracy is virtually assured-by-fabrication for our diffractive lens; it corresponds to $200 \mu \mathrm{m}$ thickness variations (in a $400 \mu \mathrm{m}$ part!), $6 \mathrm{~mm}$ lateral errors, and multi-cm out-of-plane deviations. Our interest, therefore is upon verifying much tighter, $<1 \lambda$, optical 
accuracy. This optical quality corresponds to $1 \mu \mathrm{m}$ thickness variations, $30 \mu \mathrm{m}$ lateral errors, and $4 \mathrm{~mm}$ out-of-plane deflections. The foldable diffractive lens can be built to these levels of accuracy, and we will optically verify this before launch.

The in-space optical performance of the lens will be characterized by PSF (point spread function) measurements. At present we are considering two different optical sources; either stars or a beacon. The advantage of looking at stars is that they are free, allowing us to do without a source-vehicle. The drawback is that stars provide only intermittent, relatively weak sources; a beacon is always present and can be made much brighter. While both the stellar and beacon approaches appear viable, and will be thoroughly analyzed during the Study Phase, the baseline for this proposal is to use a beacon source.

The primary complication faced in performing optical tests is the 50 meter focal length of our lens. This requires an experimental configuration, shown below, with a long separation between the lens, sensor, and beacon.

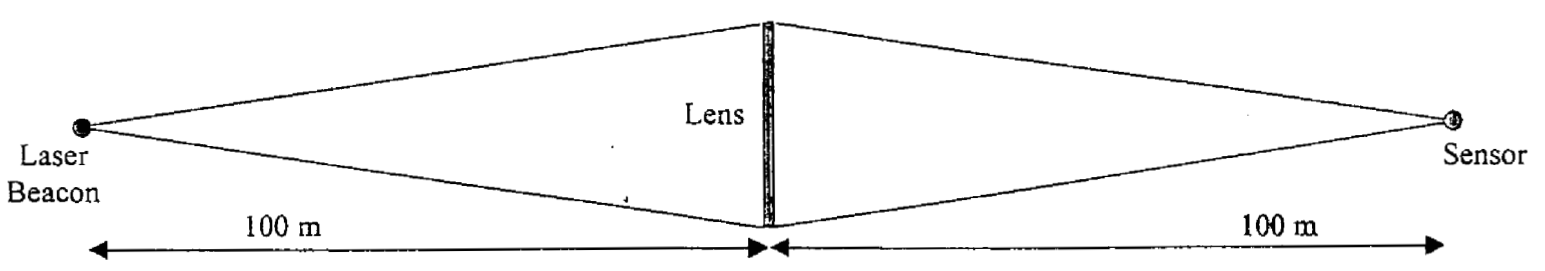

We will link the components together with tethers rather than using booms or free-flyers. For these lengths, tethers should provide a lower-mass, smaller-launch volume linkage than extendable booms, and are simpler to implement than free flying components would be.

In order to avoid the risk that the tethers will be severed by meteoroid or debris impacts, we will consider using a multistrand Hoytether ${ }^{\mathrm{TM}}$ design[4] rather than a simple single-strand fiber or the "shoelace" design of TiPS. The Hoytether ${ }^{\mathrm{TM}}$ is a tri-axial net consisting of a number of primary loadbearing lines running the length of the structure. These "primary" lines are periodically interconnected by diagonal secondary lines. Because the secondary lines are initially nearly parallel to the primary lines and slack, the structure necks down only slightly if a primary line is cut. Such a tether can suffer many cuts without catastrophic failure. The Hoytether ${ }^{\mathrm{TM}}$ also has the feature that it can be designed to be a "constant length" tether despite cuts of the lines by micrometeorites or orbital debris particles [5].

Because of the short tether lengths needed for this mission, they do not have to employ the relatively massive reel deployers used on previous tether flights. One deployment approach is to stack the tether on the outside of a hollow cylinder, another is to fold-deploy it from a narrow cartridge-case box. In the Study phase we will look at these and other simple deployer options.

A risk issue with the use of tethers for this application is the size of vibrations either induced by deployment or excited by the orbital motion of the extended system through the spatially varying gravity gradient field of the Earth. The Hoytether ${ }^{\mathrm{TM}}$ structure has a large amount of damping built into its design, so its use would insure that any initial and driven motions would be damped rapidly. In addition, judicious use of the tether length controllers on the sensor package could also allow the use of active feedback damping.

The sensor pod consists of a CCD array, a power supply, readout and storage electronics, and a communications system. We are planning to build a system as-simple-as-possible, having no active propulsion or attitude control. The pod design is further simplified by the fact that the mission-life is 
short, lasting only until the lens characterization is completed. At present, we anticipate a sensor-pod mass of $\sim 20 \mathrm{~kg}$, powered by body-mounted solar cells, and broadcasting results via an omni-antenna.

In order to perform an optical test, we need adequate signal-strength and must properly align the optical components. Use of a beacon, probably LED-based, provides a convenient, bright source. Our PSF images can only be acquired when source, lens, and sensor are adequately lined up. To avoid tight alignment tolerances governed by the limited $(\mathrm{few}-\mathrm{cm})$ size of CCD arrays, we expect to use a beacon containing an array of LED point-sources; this relaxes positioning tolerances to that of the beacon arraywidth $(30-50 \mathrm{~cm})$. To keep this experiment as simple as possible, we do not plan upon any propulsive positioning capability for the beacon or sensor pods. If the differential tether oscillations are greater than our alignment tolerances, we will either utilize active tether-tugging control or accept intermittent imaging; both options will be analyzed during the Study phase.

In addition to a full-up optical measurement of the lens performance, it will be desirable to gather separate information about the behavior of the lens and other components. Such diagnostics will greatly assist in the interpretation of the lens behavior, with or without success of the primary PSF measurements. One desirable piece of information is a visual history of the lens deployment; this will both document the post-launch integrity of the lens, as well as record its deployment. Because thermal distortions are expected to be the dominate source of errors in a successfully deployed lens, we would like to monitor thermal profiles of the lens throughout the mission. In order to accurately interpret the optical PSF measurements, it is important to know the relative positions of the lens, sensor and beacon. Sensors to acquire these diagnostic records should be part of the mission-support hardware; they may or may-not physically dwell on the sensor pod.

This flight validation mission does present challenges, which we will evaluate and seek to minimize during the Study and Refinement phases of the program. The first challenge lies in fabricating a 1.5 meter, $1 \mathrm{~kg} / \mathrm{m}^{2}$, foldable diffractive lens. Since the lens will be ground-tested prior to launch, this does not represent an actual flight-risk. The second risk lies in launching a glass lens into space. While we will seek to minimize this risk by packing-design and pre-flight shake-tests, this does represent a flight-risk. The same is true of the in-space deployment of the lens; we'll analyze and test this deployment on the ground, but actually doing it in space does involve risk. Finally, there are risks associated with the inspace optical test of the lens; these can occur either from behavior of the tether or the sensor/beacon pods. We'll limit these risks as much as possible by use of simple, high TRL, sub-systems and pre-flight analysis, simulation, and testing.

\section{Description of the current status of development, current TRL, and basis of determination}

\begin{tabular}{|l|l|l|}
\hline Component & Current TRL & Basis \\
\hline Diffractive lenses & 4 & Have been built and ground-tested \\
\hline $\begin{array}{l}\text { Space-usable diffractive } \\
\text { lenses }\end{array}$ & 3 & $\begin{array}{l}\text { Deployable support mechanism and space- } \\
\text { suitable-joints not yet demonstrated }\end{array}$ \\
\hline Tethers & 8 & Other tethers have been successfully flown \\
\hline Sensor/Beacon Pods & 8 & $\begin{array}{l}\text { Specific system must be designed and } \\
\text { implemented, but all functional sub-systems } \\
\text { have been flown }\end{array}$ \\
\hline
\end{tabular}

To date, the Diffractive Optics Group at LLNL has built and tested several high-precision (sub-wave quality) diffractive lenses. These fall into 3 classes; monolithic lenses built from cm-thick silica $(20 \mathrm{~cm}$ and $50 \mathrm{~cm}$ apertures), monolithic lenses built from $60 \mu \mathrm{m}$ polymer films $(10-50 \mathrm{~cm}$ apertures), and a 
segmented lens built from $1 \mathrm{~mm}$ silica ( $75 \mathrm{~cm}$ aperture with 6 pie-shaped segments). We are currently engaged in a project to build a 5 meter diameter foldable lens, assembled from multiple thin-glass lens segments.

Several of the monolithic lenses have been tested not only as isolated components, but as primary elements in color-corrected diffractive telescopes; successfully demonstrating that diffractive optics can be used for broadband imaging. The $75 \mathrm{~cm}$ segmented lens has demonstrated two features necessary for the proposed flight validation experiment (and for scaleup to future, multi-meter lenses); optically accurate alignment of separate lens panels, and high-precision, foldable, interpanel joints.

In addition to operational lenses, we have also demonstrated the ability to handle and to optically pattern glass films of the thickness $(400 \mu \mathrm{m})$ planned for this flight. Based upon these existing results, we believe that current diffractive lens fabrication capability falls between the TRL 4 and TRL 5 levels.

However, these lenses are not complete optical elements, as we have not yet demonstrated spacesuitable joints or a deployable support structure for holding them. As a result, we rate the status of deployable, space-usable lenses as above TRL 3, but not yet at TRL 4 .

There is operational in space right now, a tether with a design that would be adequate for the proposed technology demonstration mission. This 4-km-long tether is connecting two spacecraft with their center of mass in a $1022 \mathrm{~km}$ nearly circular orbit. The tether [6] is a 2-mm-diameter hollow braid made of the Dupont high-strength polymer fiber Spectra TM 1000 , with a breaking strength of about $45 \mathrm{~N}$, and a mass per unit length of $1.36 \mathrm{~g} / \mathrm{m}$. With its hollow braid structure and 2-mm diameter, it looks like a "fat" shoelace. The Tether Physics and Survivability (TiPS) Experiment [6] to test this tether design was launched by the Naval Research Laboratory on 20 June 1996 as a piggy-back experiment on an National Reconnaissance Office mission. The most important result of the experiment for the proposed technology demonstration mission is that the Spectra ${ }^{\mathrm{TM}}$ polymer braid of the TiPS tether has survived 4.4 years in space despite exposure to the low pressure vacuum environment, internal damage by cosmic rays and solar ultraviolet and particle radiation, chemical attack by space plasma ions, and hypervelocity impacts by micrometeorites and space debris.

Two other polymer tethers have also been successfully deployed in space. In 1993 and again in 1995 [7] a $20-\mathrm{km}$-long Spectra ${ }^{\mathrm{TM}}$ tether the size of kite string was successfully deployed within a few tens of degrees of local vertical In all three cases, the deployment was started with springs, while the gravity gradient forces completed the job.

So, while the specific tether used in this experiment will not have flown before, other tethers bave; we rate the tether TRL as 8 .

\section{Approach to reach TRL 4 or higher at the end of the six month Study Phase}

During the Study phase we will further develop diffractive lens technology to insure that its spacesuitability and deployability aspects are raised to TRL 4 status. This effort will focus upon demonstrating a deployable support-rim and developing space-suitable inter-panel joints.

The attributes desired for the deployable rim are that it be as simple and low-mass as possible, while not (via structural imprecision or thermal mismatches) itself inducing large lens distortions. The latter concerns call for a loosely-coupled rim, with structurally-compliant, low-conductivity linkage to the lens, not a tightly-coupled design. At present our primary focus is upon "coordinated" designs in which the rim has the same folding pattern as the outer edge of the lens, but is not rigidly connected to it. This permits 
the lens-rim connections to maintain finite, but nearly-constant, separations throughout the stowed, middeployment, and operational configurations.

We will investigate these different deployable rim designs during the early part of the Study phase. After evaluating and comparing these options, we will downselect to one approach, and build and test a deployable rim by the completion of the Study phase. This deployable rim development will raise the TRL status of deployable diffractive lenses to TRL 4. At this point we will have separately demonstrated the deployablity of both diffractive lenses and their support rims. The combination of these two components into a single, coordinated, system will be necessary to reach TRL 5 , and will be a focus of the Refinement phase of the program.

The other aspect of lens development which we'll work on during the Study phase, is space-suitable joints. To date, most of our research has been devoted to flexible-seam joints, in which thin metal foil is used to connect panels together. These joints have the virtue of extreme simplicity, and no moving parts. When the lens is folded, each joint is rolled through $180^{\circ}$; as long as the foil is thin enough (and bend radius large enough) the material remains elastic, and the joint retains high lateral precision. Our current seam design ( 1.5 mil Ti-alloy foil for a segmented $75 \mathrm{~cm}$ lens) is fine for earth-based lenses, but will likely not be adequate for future space applications; the concern being thermal mismatch between the lens and seams. In space we expect the lens and seams to reach different temperatures, as well as suffering from different CTE values; this combination will cause in-plane distortions and degrade the lens's optical performance. While these difficulties will present no problem in reaching a $200 \lambda$ level of performance, they are not acceptable for the $1 \lambda$ performance we wish to demonstrate. Accordingly we will pursue improved joint designs during the Study and Refinement phases. At present we are considering several improvements, including better T-matched metal seams (via low a/e coatings on the seam), polymer seams to improve both T and CTE match to the glass (based on transparent, low-CTE polyimides), and alternative joint approaches such as glass hinges. During the Study phase we will likely concentrate upon the polyimide approach, making and testing glass-polyimide seamed assemblies.

\section{End-to-end technology development and validation approach leading to flight validation}

There are several thrusts to the preflight development effort. The first is carrying-out the pre-flight development needed to respond to the technology challenges detailed before. In addition, the development program must also detail the mission plan for the flight experiment, and assemble and integrate the full flight vehicle (lens plus subsidiary components).

Study Phase: During the Study phase we'll concentrate on two tasks; raising the status of deployable diffractive lenses to TRL 4, and refining the mission plan for the flight validation experiment.

The flight plan presented earlier in this proposal is conceptually clear, but remains flexible in a number of respects. During the Study phase we will examine a number of such mission options and downselect between them, arriving at a coordinated mission plan. We will also perform preliminary designs of the non-lens components (primarily the sensor-pod, and tether) of this flight experiment.

Two of the design choices to be made concern the lens; we will settle on a lens diameter and a folding pattern. The primary factors in determining the lens aperture are the size of readily available glass sheets, the shape and size of the folded-up lens, and the implied lens-sensor-beacon separations. The issues involved in selecting a folding pattern are again the size and shape of the folded-up lens, the ease of protecting the folded-up shape from launch vibrations, as well as its impact on lens fabrication and assembly. 
The two most important mission decisions to be made during the Study phase are the optical source (stars or beacon) and the orbit (LEO or GTO). Using stars for PSF measurements results in a lighter, simpler test-vehicle (no beacon, and one 50 meter tether instead of dual 100 meter ones). The advantage of using a beacon is, of course, that it provides a much brighter, more continuously available source. The orbital choice will likely be determined both by our preference as a test-location (tether-use is simpler in circular orbits), and the availability and cost of launch opportunities. At present our preference is for a beacon source and for LEO.

The other activity during this phase is to develop a preliminary design for the sensor-pod, the beacon, and the tethers. These designs are, of course, closely linked to the above optical-source and orbitallocation decisions.

The sensor-pod design will concentrate upon basic choices for the vehicle bus, power-supply, communications system, PSF and diagnostic sensors, and control system; it will also deliver a massbudget and vehicle layout.

The tether study will examine a number of issues. It will determine the form of tether (i.e., Hoytether $^{\mathrm{TM}}$, single fiber, shoelace, etc.) to be used, considering aspects such as mass, risk-of-breakage, length variability and damping. The study will determine the most suitable (reliable and low-mass) tether deployment mechanism; this may involve a long counter-weighted bias. We will use simulation tools such as the TUI TetherSim ${ }^{\mathrm{TM}}$ program to investigate whether gravity gradients or centrifugal force are more suitable for tensioning the tethers. During this phase, we will also use the tether dynamics simulation program, TetherSim ${ }^{\mathrm{TM}}$, which has the Earth's gravity field to the $\mathrm{J} 8 \mathrm{term}$, to determine the extent of the tether oscillations to be expected for various different orbits.

Refinement Phase: During the Refinement phase we'll concentrate on two tasks; raising the status of deployable diffractive lenses to TRL 5, and performing more detailed design and readiness-validation for the auxiliary components (tether and sensor/beacon pods) of the flight experiment.

The progression of diffractive lens readiness to TRL 5 will focus on two developments; demonstration of an integrated lens-rim deployment, and performing shake-tests of packaged lens assemblies. Because the diffractive patterning of a glass lens involves only the upper few microns of its surface, these mechanical tests can be performed with blank surrogate lenses; they do not have to wait for fully patterned lenses.

The other activity during this phase is to finalize the design of the auxiliary flight systems and validate key components. We will design and fabricate the tether deployment system. This hardware will then be ground tested with the chosen tether flexware. We will also determine whether drop-tower or zero-gee-airplane deployment tests will be useful, and will finalize software design for tether deployment and dynamics control. The subsystem designs for the sensor/beacon pods will be finalized during this period. If ground-based validation tests are deemed necessary for certain subsystems or components they will be done during this phase.

Implementation Phase: The focus during the Implementation phase is final design, procurement, fabrication and integration of the flight hardware. Before flight we will perform an optical groundvalidation test of the completed diffractive lens. The flight hardware will undergo pre-flight shake and validation testing.

The key activities of the flight-validation mission will be controlled by a combination of high-level (strategic) commands from the ground, and low-level (tactical) control on the spacecraft. Flight data (both 
hardware diagnostics and optical PSF measurements) will be relayed to the ground for analysis and action by the mission controllers.

\section{Methods planned to identify and mitigate development, performance, schedule \& cost risks}

The technology risks are mitigated by ground demonstrations and test prior to launch. The primary technology risk in the optic is the hinge mechanism which is undergoing development and testing as part of the LLNL funded LDRD project. The deployment mechanism will also undergo ground simulation tests. Finally the assembled spacecraft will undergo the usual environment ground tests such as shake tests.

The cost and schedule risks are expected to be primarily in the spacecraft design and fabrication. To the degree possible we plan to utilize commercial or existing spacecraft hardware to minimize these risks. If possible the only non-standard hardware will be the lens and the tether system. Even the tether will be an adaption of a commercial design developed by Tethers Unlimited.

\section{Management Section}

\section{Capabilities and past performance of the Technology Provider and partners}

The Technology Provider for this diffractive lens technology development is Dr. Roderick Hyde of the Diffractive Optics Group at the Lawrence Livermore National Laboratory (LLNL).

Dr. Hyde originated the concept of using diffractive lenses to provide large aperture, lightweight space telescopes in 1996. This approach, under the name of Eyeglass, has been actively investigated by Dr. Hyde and feilow researchers at LLNL from 1996 to the present time. During this time this team has performed detailed system and optical designs of full-scale Eyeglass telescopes, developed the ability to fabricate sub-wave quality diffractive lenses (from silica, thin-glass, and thin polymers), and has built and successfully tested broad-band diffractive telescopes.

The Diffractive Optics group at LLNL is the world-leader in fabrication of meter-class diffractive optics, having made and delivered $\sim 30$ such optics to customers throughout the world. It is currently preparing to manufacture several hundred $40 \mathrm{~cm}$-sized optics to the LLNL NIF laser fusion project. In addition to these large optics, it has fabricated numerous smaller gratings including specialized bigh damage gratings and a previous high quality grating for NASA

In FY2000 this LLNL team began a three year project to demonstrate the ability to fabricate largesize diffractive lenses. The target for this effort is a lightweight, 5 meter aperture, foldable lens, assembled by joining together multiple thin-glass lens panels. The 1.5 meter lens proposed for this NMP technology development falls between the 81 panel, 5 meter size lens planned for completion at LLNL in 2002 and the 6 panel, 0.75 meter lens already demonstrated in 2000 . Accordingly, the Technology Provider has a high degree of confidence in being able to develop and deliver a flight-worthy 1.5 meter lens in support of a flight-validation mission in 2003-2004.

LLNL is partnering with two other organizations, the Jet Propulsion Laboratory (JPL) and Tethers Unlimited Incorporated (TUI) to jointly provide spaceflight expertise and hardware necessary for this project. Basically, LLNL will provide the deployable diffractive lens, JPL will provide the sensor and beacon spacecraft, and TUI will provide the tethers to link the three platforms together. JPL will take the lead in integrating these subsystems together and performing the spaceflight to verify this technology. 
The Jet Propulsion Laboratory is the world expert in developing, and flying unmanned space vehicles for advanced science and technology missions. They are unique in combining both the ability to implement new, one-of-a-kind, missions and hardware with the institutional experience-base of having done so for over 40 years involving many widely-differing missions. Accordingly, JPL is very well qualified both to successfully develop and implement the sensor and beacon components as well to carryout the actual validation flight.

If this proposal is successful, JPL will provide both mission and system architecture design support to LLNL in the development of the flight system concept for this technology demonstration. This will include performing mission and flight system design trades to evaluate experiment implementation concepts, and to identify and recommend suitable launch, spacecraft bus, and sensing/instrumentation options. JPL will work jointly with Tethers Unlimited, Inc. to address integration and deployment of the tether system. JPL will also work jointly with LLNL to establish launch packaging, survivability, and deployment of the test article.

Tethers Unlimited, Inc. is a pioneer in the design and implementation of space tether technologies. TUI has developed several commercial applications of space tethers, such as the Terminator Tether ${ }^{\mathrm{TM}}$ Deorbit Device. TUI also has experience in the development of innovative tether technologies (such as the HoytetherTM) and numerical simulation tools (such as TetherSim ${ }^{\mathrm{TM}}$ ). Accordingly, TUI is very well qualified to successfully develop and implement the tethers necessary for this project.

\section{Project organization and study phase management}

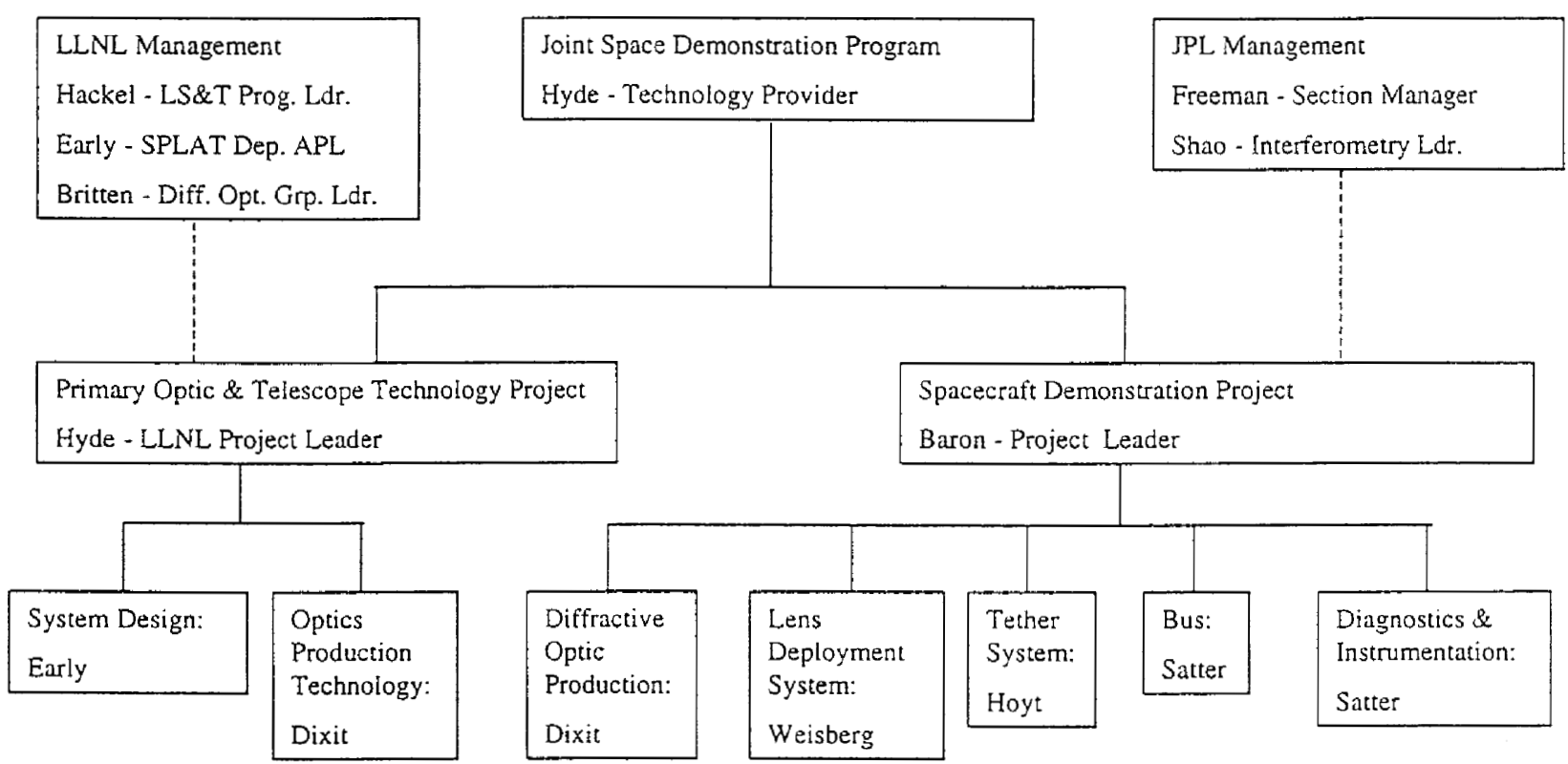

\section{Commitment/contributions of personnel and organizations}

Dr. Hyde, the Technology Provider, will be working full time on projects supporting the "Eyeglass" diffractive lens technology. He is part of a larger Diffractive Optics group whose other primary product is meter scale diffraction gratings for laser fusion programs around the world and at LLNL. The personnel and facilities of this group will be utilized in this project.

LLNL is providing $\$ 900 \mathrm{k}$ in FY01 internal Laboratory Directed R\&D (LDRD) funds to support the development of the basic diffractive optics technology. Dr. Hyde is the Principle Investigator for this 
internal project. This project bas a $\$ 900 \mathrm{k}$ FY02 (pending) budget. The primary objective is to build a 5 meter ground demonstration optic using scalable, space capable technology. Dr. Dixit and Dr. Weisberg are key members of this project; Dixit is in charge of proctucing lens panels and Weisberg for assembling them into the 5 meter lens.

Mis. Satter is a Senior Member of Technical Staff in JPL's Mission and Systems Architecture Section. Ms. Satter's work assignments are flexible, and her management is committed to supporting this activity, so she can be available as appropriate to support this activity and has access to all necessary support at JPL.

\section{Basis and justification for the Study Phase cost and schedule.}

LLNL has produced a $50 \mathrm{~cm}$ single segment and a $75 \mathrm{~cm}$ multi-segment diffractive lens. A general schedule and cost estimate was produced for the current project to perform a ground demonstration of a 5 $m$ diffractive optic. These past efforts were used as the basis for estimating the initial design phase cost and schedules for the proposed Study Phase of a $1.5 \mathrm{~m}$ optic for a space deployment demonstration.

JPL has produced and flown many small satellites. The schedule and cost for performing a conceptual spacecraft design and trade-off study was based on this experience.

\section{End-to-end cost estimate}

Based upon a preliminary review by the JPL Spacecraft Design Team, and incorporating possible commercial hardware, we estimate the total project cost to be $7-10 \mathrm{M}$.

\begin{tabular}{|l|ccc|c|}
\hline ROM Costs (K\$) & Study Phase & Refinement Phase & Implementation & Total \\
\hline Deployable Lens & 150 & 500 & 1000 & 1650 \\
Tether Systems & 50 & 200 & 600 & 850 \\
Mission Implementation & 150 & 900 & 6000 & 7050 \\
\hline Total Project & 350 & 1600 & 7600 & 9550 \\
\hline
\end{tabular}

\section{Access to space approach}

During the Study phase, Celeste Satter of JPL will be responsible for developing the project's accessto-space approach. In order to keep end-to-end mission costs low and minimize development, cost, performance, and schedule risk we plan to use a commercial spacecraft bus and secondary or shared commercial launch services. Secondary payload accommodations on a Delta-II launch vehicle can accommodate this mission, and several low-cost shared opportunities which would meet our requirements are currently being advertised for Pegasus XI launch vehicles. Projected availability of such opportunities for the 2003-2004 timeframe is not currently available, however this mission has no driving launch schedule constraints, so we can be flexible in adapting to available opportunities. STS Hitchhiker small payload services are another option for low-cost space access, however we would prefer a higher orbit than STS achieves for minimization of aerodynamic drag effects, and safety issues may be of concern if we attempt to deploy a large, frangible lens in the vicinity of the Shuttle.

In addition to exploring launch as a secondary payload on commercial vehicles or the Space Shuttle, we will participate in the New Millennium Carrier study. During their study, we will provide them with our project's mass, volume, and orbital-location requirements. 


\section{Proposed Personnel}

Dr. Roderick Hyde from the LLNL Diffractive Optics group will be the Technology Provider or Program Leader under this proposal. He will be responsible for coordination and integration between the JPL, TUI and LLNL teams.

Dr. Jim Early from LLNL is the Deputy Assist. Program Leader for the Short Pulse Laser Applications \& Technology Group which includes the Diffractive Optics Group. He will focus on the optical systems design effort and the engineering for space operation.

Dr. Shamasundar Dixit from the LLNL Diffractive Optics group will be responsible for production and test of the diffractive lens flown in this program.

Dr. Andrew Weisberg from the LLNL Physics and Advanced Technology Directorate will be responsible for the diffractive lens's deployable support-rim.

Drs. Richard Baron at JPL will have overall responsibility for this project at JPL and will be responsible for integration with the long term JPL diffractive optic telescope development program.

Celeste Satter at JPL will be responsible for the design, testing, and integration of the flight system used to carry out this experiment. She will also be responsible for launch vehicle integration, and will coordinate the development and implementation of the flight and ground data systems.

Dr. Michael Shao will be a senior technical advisor and will be responsible for integration with the long term JPL advanced optics and interferometry efforts.

Dr. Robert Hoyt at TUI will be responsibie for the design, testing and delivery of the tethers used in this project's flight experiment.

The resumes for these key personnel are included at the end of this proposal. 


\section{References}

1. R. Hyde, "Eyeglass, A Large Aperture Space Telescope", UCRL-DD-13626, (internal final report on LDRD Exploratory Research Project: 97-ERD-060), Lawrence Livermore National Laboratory, (2000).

2. R Hyde, "Eyeglass. 1. Very Large Aperture Diffractive Telescopes" Applied Optics 38, No.19, 4198-4212, (1 July 1999).

3. Kurland, R, Stella P., "Current Results from the Advanced Photovoltaic Solar Array", IECEC Proceedings, August 1993

4. Forward, R.L. and R.P. Hoyt, "The Hoytether: A Failsafe Multiline Space Tether Structure", Proceedings of the Tether Technology Interchange Meeting, Huntsville, AL, 1997.

5. Forward, R.L., Failsafe Multistrand Tether Structures for Space Propulsion, Final Report by Forward Untimited on Contract NAS8-39318 with NASA/MSFC, Huntsville, AL 35812, 1992. [See also AIAA preprint 92-3214, 28th Joint Propulsion Conference, Nashville, TN, 1992.]

6. Barnes, J, "TiPS: Results Of A Tethered Satellite Experiment", Proceedings of the Tether Technology Interchange Meeting, Huntsville, AL, 1997. [See also web page <http:/hyperspace.nrl.navy.mil/tips $>$ ]

7. Carroll, J.A., "SEDS Deployer Design and Flight Performance," paper WSEDSA-1 at Fourth International Conference on Tethers in Space, Washington DC, 1995. 


\section{Facilities and Equipment}

Diffractive Optics Processing Facilities and Equipment: The Diffractive Optics Group fabrication facilities will be used for LLNL funded supporting activities during the Study and Refinement Phases. They will be then used during the Implementation Phase for smoothing and patterning the lens panels used for the ST-6 flight-lens. Some of these facilities are shown in photographs on the following page: The photoplotter is capable of writing 1 meter photolithography masks. We will primarily use it for metrological inspection of finished lens panels. The meniscus coater is capable of applying uniform coatings to 1 meter-wide parts. We will use it to apply photoresist to lens panels during their photolithographic processing. The diffractive optics fabrication facility shown is one of two operated by the Group. These sites are where panels will be smoothed and patterned. Equipment used in these facilities include the coaters, etchers, mask aligners, and etch-inspectors.

Lens Assembly Facility and Equipment: The Lens Assembly Machine will be used to assemble a 5 meter ground demonstration lens under another NASA proposal and the space demonstration lens for this proposal. This facility is located in a clean-room in Building 174 at LLNL. The assembly machine is currently being designed and built as part of the Eyeglass 5 meter Lens Strategic Initiative at LLNL.

\section{Diffractive Optics Facilities at LLNL}

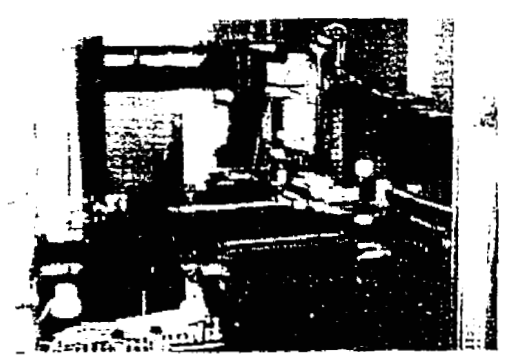

Fig. 1 Photo-plotter for writing binary masks \& for motrologlcal inspaction

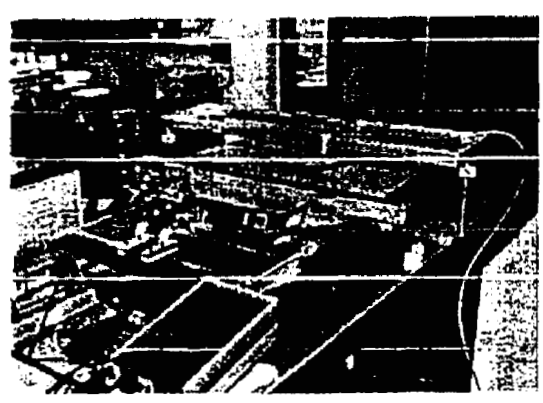

Fig. 2 Meniscus coster for dopositing flat contings

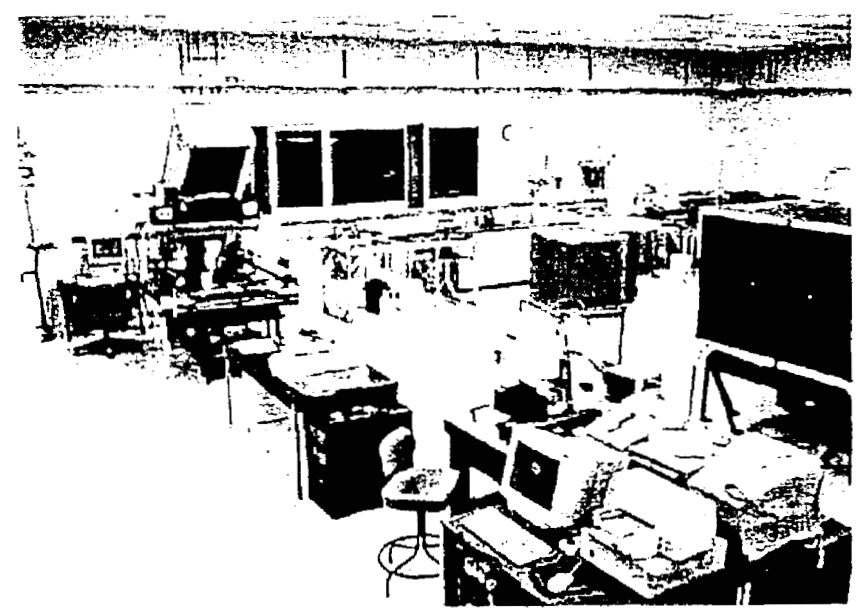

Fig. 3 Diffractive optics fabrication facillty at LLNL 


\section{Current and Pending Support}

\section{LLNL internal research project: FY01 - \$900k, FY02 - \$900k(pending)}

This basic diffractive telescope concept and technology has been developed under LLNL internal Laboratory Directed Research \& Development (LDRD) funds. At present Dr. Roderick Hyde is the Principal Investigator of a LDRD Strategic Initiative (SD) project aimed at the fabrication of a 5 meter aperture diffractive lens, assembled from multiple thin glass lens panels; this project is pioneering the fabrication techniques (and creating the assembly tools) which will be employed for the ST-6 lens. LDRD SIs are normally three year projects, but are reviewed and funded on a year-by-year basis. The diffractive lens SI is currently beginning its $2^{\text {nd }}$ year, so the FY02 funding will be the last year of funding under the LDRD rules; because of the yearly review process, the FY02 funding is listed as "pending". It should be noted that LDRD projects incur significantly lower overhead fees than externally funded research; the 900 $\mathrm{K} \$$ yearly funding for this project corresponds to about $1700 \mathrm{KS}$ of external funding.

This project has focused on scaling lightweight diffractive lens technology to multi-meter scale and demonstrating the technology with space rated materials. The project has developed technology for fabricating large glass substrates that meet strict $(\lambda / 10)$ optical thickness requirements and for etching the diffractive optic patterns onto these substrates. The project is developing the hinge and metrology technology to join meter scale pieces into large scale telescope primaries. During FY00 a $75 \mathrm{~cm}$, six section optic was fabricated to demonstrate these technologies. The project is also performing systems studies for the folding, packaging and deployment of these optics as well as space operations of the telescopes.

\section{Gossamer Spacecraft Initiative (NRA 00-OSS-06) proposal by LLNL on diffractive optics fabrication and testing: FY01 - \$200k (pending), \$500k in`02 \&`03 (pending)}

This proposal will support the fabrication and ground testing of a 5 meter diameter, $1 \mathrm{~kg} / \mathrm{m}^{2}$ diffractive phase plate telescope. The primary optic of this ground demonstration telescope will use the same technology as the lens to be deployed in space in the Implementation Phase of this proposal. Dr. Hyde is the Principal Investigator.

\section{Gossamer Spacecraft Initiative (NRA 00-OSS-06) proposal by JPL on diffractive optic space telescope design: FY01 - \$200k (pending). \$500k in`02 \& 03 (pending)}

A study of multi-aperture interferometer and single aperture space telescope architectures and technology utilizing diffractive phase plate optics. The telescopes would be used to identify, spectrally analyze and eventually image extra-solar terrestrial planets. This study will develop the critical positioning and control technologies necessary to utilize this technology in space telescopes. Dr. Baron is the Principal Investigator

\section{Gossamer Spacecraft Initiative (NRA 00-OSS-06) proposal by LLNL on related solar sail telescopes: FY01-\$150k (pending)}

A study to develop related technology of amplitude zone plates made of solar sail materials for use as space telescope optics. The study will not directly support the technology to be used in the present proposal. Dr. Early is the Principal Investigator. 


\section{Study Phase Proposed Cost and Schedule}

The schecule for Study phase is shown below; the start date is assumed to be on or about $2 / 12 / 01$. These activities are discussed in more detail in the Technical Section.

\section{Study Phase Schedule}

Deployable Rim:

Design

\section{Months}

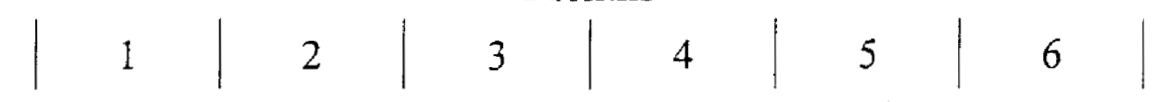

Fab \& Test

Space-suitable Seams:

Material Dev.

Test Assemblies

Mission Planning:

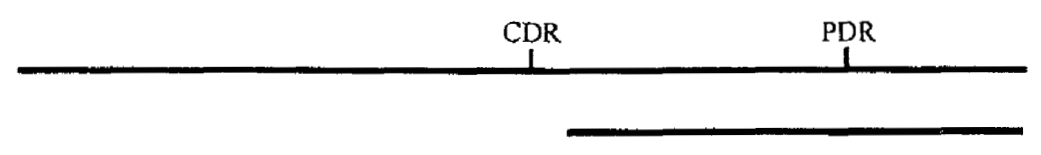

Sensor/Beacon Design:

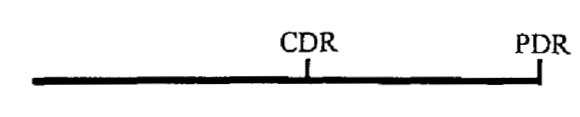

Tether Design:

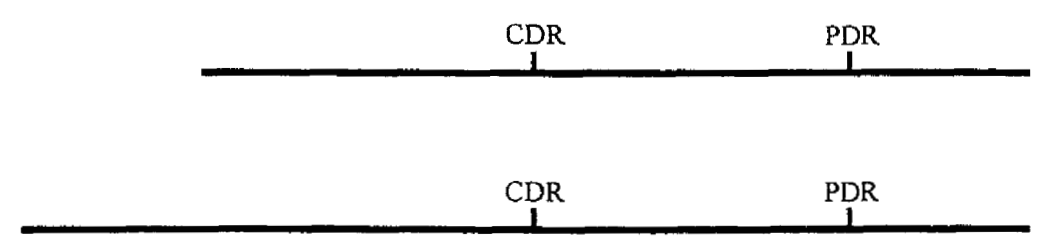

\section{NMP ST-6 Meetings}

CDR : Conceptual Design Review

PDR : Preliminary Design Review

The proposed expenditures during the Study phase are summarized on the following "Cost Elements Breakdown" forms. In preparing these it is assumed that funding for JPL activities is sent directly to JPL rather than being processed through LLNL; this procedure should be more efficient and minimize overhead fees. 
The Study phase is, of course, just the initial phase of the ST-6 project. An overview of the full schedule of planned activities is shown below:

\section{Full ST-6 Schedule}

Study Phase:

Lens

Mission

Vehicle

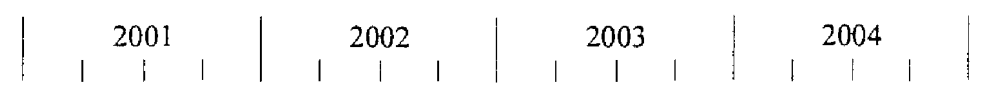

Refinement Phase:

Deployable Lens

Lens Packing Dev.

Tether Deployer Dev.

Pod Component Eval.

Implementation Phase:

Detailed Mission Plan

Lens Fabrication

Tether/Deployer Fab.

Sensor/Beacon Ass.

Vehicle Integration

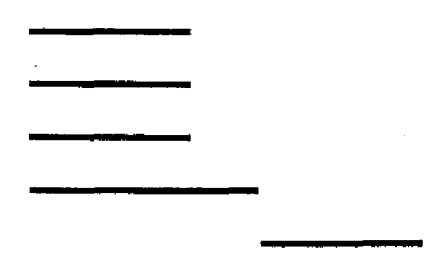

Verification Flight: 
LLNL plus JPL Costs

\section{COST ELEMENTS BREAKDOWN (SHORT FORM)}

\begin{tabular}{|c|c|c|c|}
\hline COST ELEMENTS & & & \\
\hline DIRECT LABOR (Hours by labor category) & HOURS & RATE & AMOUNT \\
\hline & & $\$$ & $\$$ \\
\hline & & $\$$ & $\$$ \\
\hline LLNE Labor & & $\$$ & $\$ 48,143$ \\
\hline & & $\$$ & $\$$ \\
\hline JPL Labor & & $\$$ & $\$ 50,700$ \\
\hline & & $\$$ & $\$$ \\
\hline & & $\$$ & $\$$ \\
\hline & & $\$$ & $\$$ \\
\hline & & $\$$ & $\$$ \\
\hline & & $\$$ & $\$$ \\
\hline & & $\$$ & $\$$ \\
\hline TOTAL DIRECT LABOR & & 6 & $\$ 98,843$ \\
\hline OVERHEAD & BASE & RATE & $\ldots$ \\
\hline LLNL Labor & & & $\$ 22,575$ \\
\hline & & & $\$$ \\
\hline JPL Labor & & & $\$ 24,800$ \\
\hline & & & $\$$ \\
\hline & & & $\$$ \\
\hline & & & $\$$ \\
\hline TOTAL OVERHEAD & & 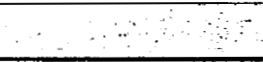 & $\$ 47.375$ \\
\hline MATERIAL COST & & 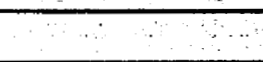 & $\$ 2,500$ \\
\hline MATERIAL BURDEN & & & $\$ \quad 250$ \\
\hline TOTAL MATERIAL & & & $\$ 2,750$ \\
\hline SUBCONTRACT COST & & & $\$ 58,000$ \\
\hline SUBCONTRACT BURDEN & & & $\$ 15,400$ \\
\hline TOTAL SUBCONTRACT & & & $\$ 73,400$ \\
\hline OTHER DIRECT COSTS (Travel, etc.) & & & $\$$ \\
\hline & & & $\$$ \\
\hline LLNL Trave 1 & & & $\$ 2,500$ \\
\hline JPL Travel & & & $\$ 5,000$ \\
\hline & & & $\$$ \\
\hline & & & $\$$ \\
\hline TOTAL ODC & & & $\$ 7,500$ \\
\hline SUB-TOTAL COST & & & $\$ 229,868$ \\
\hline TOTAL GENERAL \& ADMINISTRATIVE & & & 120,130 \\
\hline TOTAL COST & & & $\$ 349,998$ \\
\hline PROFIT/FEE & & $\%$ & $\$$ \\
\hline TOTAL PRICE & & & $\$ 349,998$ \\
\hline
\end{tabular}




\section{COST ELEMENTS BREAKDOWN (SHORT FORM)}

\begin{tabular}{|c|c|c|c|}
\hline \multirow{2}{*}{$\begin{array}{l}\text { COST ELEMENTS } \\
\text { DIRECT LABOR (Hours by labor category) }\end{array}$} & & & \\
\hline & HOURS & RATE & AMOUNT \\
\hline & & $\$$ & $\$$ \\
\hline LLNL Hours & 830 & $\$ 58.00$ & $\$ 48,143.00$ \\
\hline & & $\$$ & $\$$ \\
\hline & & $\$$ & $\$$ \\
\hline & & $\$$ & $\$$ \\
\hline & & $\$$ & $\$$ \\
\hline & & $\$$ & $\$$ \\
\hline & & $\$$ & $\$$ \\
\hline & & $\$$ & $\$$ \\
\hline & & $\$$ & $\$$ \\
\hline & & $\$$ & $\$$ \\
\hline TOTAL DIRECT LABOR & & & $\$ 48,143.00$ \\
\hline OVERHEAD & BASE & RATE & 28 \\
\hline & & & $\$$ \\
\hline ILNT_Labor & $48,143.00$ & 0.469 & $\$ 22,575.00$ \\
\hline & & & $\$$ \\
\hline & & & $\$$ \\
\hline & & & $\$$ \\
\hline & & & $\$$ \\
\hline TOTAL OVERHEAD & $\therefore$ & 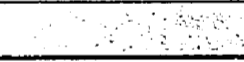 & $\$ 22,575.00$ \\
\hline MATERIAL COST & & m & $\$ 2,500.00$ \\
\hline MATERIAL BURDEN & & & $\$ \quad 250.00$ \\
\hline TOTAL MATERIAL & & & $\$ 2,750.00$ \\
\hline SUBCONTRACT COST & $\therefore$ & 3 & $\$ 8,000.00$ \\
\hline SUBCONTRACT BURDEN & & & $\$ 1,000.00$ \\
\hline TOTAL SUBCONTRACT & & & $\$ 9,000.00$ \\
\hline OTHER DIRECT COSTS (Travel, etc.) & & 24 & $\$$ \\
\hline & & 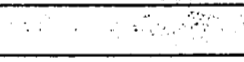 & $\$$ \\
\hline Trave1 & & 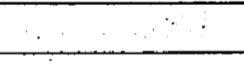 & $\$ 2,500.00$ \\
\hline & & 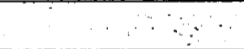 & $\$$ \\
\hline & & & $\$$ \\
\hline & & & $\$$ \\
\hline TOTAL ODC & & & $\$ 2.500 .00$ \\
\hline SUB-TOTAL COST & & & $\$ 84,968.00$ \\
\hline TOTAL GENERAL \& ADMINISTRATIVE & & & 65.030 .00 \\
\hline TOTAL COST & & & $\$ 149,998.00$ \\
\hline PROFIT/FEE & & $\%$ & $\$$ \\
\hline TOTAL PRICE & & & $\$ 149,998.00$ \\
\hline
\end{tabular}


JPL Costs

COST ELEMENTS BREAKDOWN (SHORT FORM)

\begin{tabular}{|c|c|c|c|}
\hline \multirow{2}{*}{$\begin{array}{c}\text { COST ELEMENTS } \\
\text { DIRECT LABOR (Hours by labor category) }\end{array}$} & & & \multirow[b]{2}{*}{ AMOUNT } \\
\hline & HOURS & RATE & \\
\hline & & $\$$ & $\$$ \\
\hline & & $\$$ & $\$$ \\
\hline JPL Labor & & $\$$ & $\$ 50,700$ \\
\hline & & $\$$ & $\$$ \\
\hline & & $\$$ & $\$$ \\
\hline & & $\$$ & $\$$ \\
\hline & & $\$$ & $\$$ \\
\hline & & $\$$ & $\$$ \\
\hline & & $\$$ & $\$$ \\
\hline & & $\$$ & $\$$ \\
\hline & & $\$$ & $\$$ \\
\hline TOTAL DIRECT LABOR & & & $\$ 50,700$ \\
\hline OVERHEAD & BASE & RATE & \\
\hline & & & $\$$ \\
\hline & & & $\$$ \\
\hline JPL Labor & & & $\$ 24,800$ \\
\hline & & & $\$$ \\
\hline & & & $\$$ \\
\hline & & & $\$$ \\
\hline TOTAL OVERHEAD & 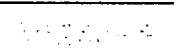 & $\ldots$ & $\$ 24,800$. \\
\hline MATERIAL COST & - & 2 & $\$$ \\
\hline MATERIAL BURDEN & & & $\$$ \\
\hline TOTAL MATERIAL & & & $\$$ \\
\hline SUBCONTRACT COST TWI & 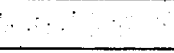 & 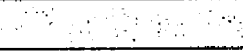 & $\$ 50,000$ \\
\hline SUBCONTRACT BURDEN & & & $\$ 14,400$ \\
\hline TOTAL SUBCONTRACT & $\ldots$ & $\therefore \cdots$ & $\$ 64.400$ \\
\hline OTHER DIRECT COSTS (Travel, etc.) & & 3 & $\$$ \\
\hline & & $\therefore a$ & $\$$ \\
\hline Travel & & & 5,000 \\
\hline & & & $\$$ \\
\hline & & & $\$$ \\
\hline & & & $\$$ \\
\hline TOTAL ODC & & & 5,000 \\
\hline SUB-TOTAL COST & & & $\$$ \\
\hline TOTAL GENERAL \& ADMINISTRATIVE & & & 55,100 \\
\hline TOTAL COST & & & $\$ 200,000$ \\
\hline PROFIT/FEE & & $\%$ & $\$$ \\
\hline TOTAL PRICE & & & $\$ 200,000$ \\
\hline
\end{tabular}




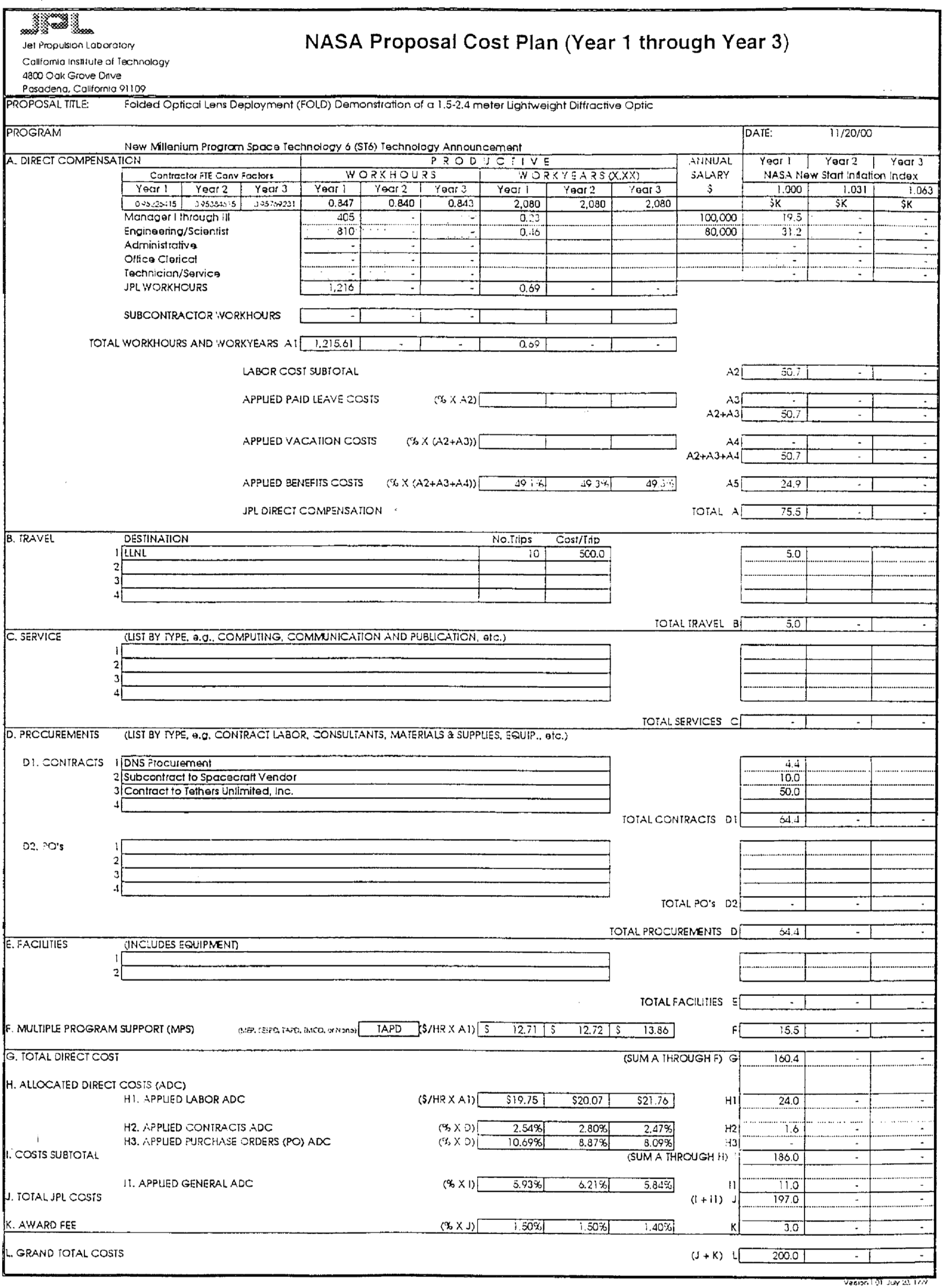




\begin{tabular}{|l||}
\hline PROPOSAL TITLE: \\
Folded Optical Lens Deployment (FOLD) Demonstration of a 1.5-2.4 meter Lightweight Diffractive Optic \\
PROGRAM: \\
New Millenium Program Space Technology 6 (ST6) Technology Announcement
\end{tabular}

\section{Study Phase Budget Summary (\$K)}

For Period From 4-1-2001 to 9-30-2001

1 Direct Labor (saiaries, wages, and fringe benefits)

2 Other Direct Costs:

a. Subcontracts

b. Services

c. Equipment

d. Supplies

e. Travel

f. Other (MPS \& ADC)

3 Facilities and Administrative Costs

4 Other Applicable Costs: (Award Fee)

5 SUBTOTAL-Estimated Costs

6 Less Proposed Cost Sharing (if any)

7 Total Estimated JPL Costs

8 Other NASA Center Costs

9 APPROVED BUDGET
A

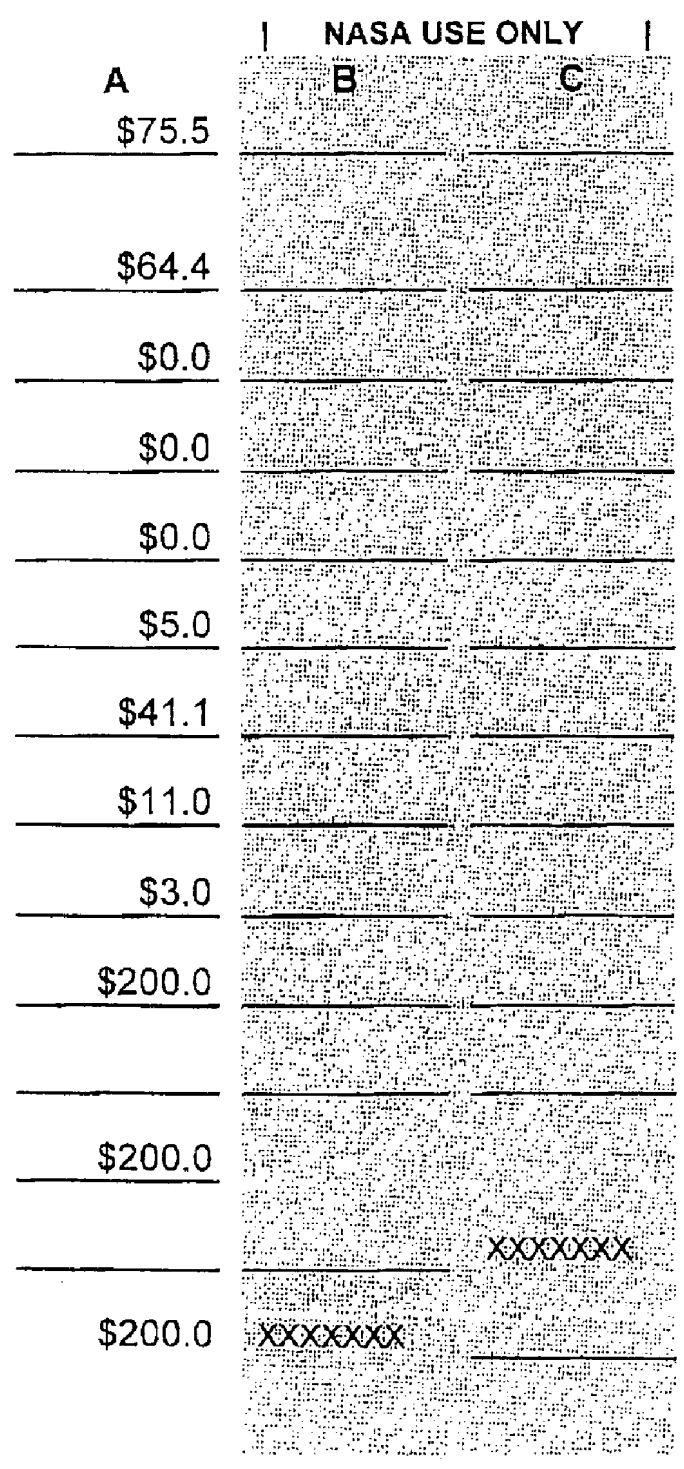




\section{JPL Cost Accumulation System}

The NASA prime contract-NAS7-1407-is a Cost Reimbursable Award Fee type instrument. All costs incurred are billed to the Government on a $100 \%$ reimbursable basis. The costs to be charged for the proposed work must be consistent with contractual provisions and established procedures for costing under the current contract between NASA and Caltech. All charges developed at the Laboratory, including JPL applied burdens, are billed to the Government as direct charges at the rates in effect at the time the work is accomplished. Government audit is performed on a continuing basis by a Defense Contract Audit Agency team in residence.

Allocated Direct Costs (ADC) is the term for "JPL applied burdens." ADC includes activities (accounts) benefiting multiple tasks. The cost collection system groups common Allocated Direct Cost accounts into three groups. The groups are as follows:

1) Labor: Labor $A D C$

2) Procurement: Purchase Order ADC and Subcontract ADC.

3) General: a percentage of all subordinate costs on direct projects. (Similar to the General and Administrative expense in industry.)

Each grouping contains like functions or activities. The accounting process distributes these costs on a $100 \%$ reimbursable basis.

Multiple Program Support (MPS) is a distributed direct factor per JPL and accountable contractor workhour on respective program office direct accounts.

Labor-Employee Benefits consist of three labor fringe rates applied to direct labor as follows:

- Paid leave is a percentage of straight time labor costs.

- Vacation is a percentage of straight time labor cost and paid leave costs

- Benefits is a percentage of straight time and overtime labor costs, paid leave costs, and vacation costs.

Award Fee the NASA Caltech contract for the operation of the federally funded research and development center (FFRDC) is a cost plus award fee contract. As such, all sponsors placing funds on contract contribute a small percentage of task order doliars toward the award fee.

For this proposal the estimated costs have been built up in the same manner as above. However, their presentation in the required tables have been adapted in the following ways:

1. The costs for all three Employee Benefit components are included in the Direct Labor costs stated in this proposal.

2. Labor and Procurement ADC along with MPS costs are displayed in the "Other" category in the Other Direct Costs section.

3. Since the JPL General ADC costs are similar to G\&A and are derived in the same fashion-a percentage of the subtotal of all costs-they are displayed in the Facilities and Administrative Costs section.

4. The Award Fee is displayed in the Other Applicable Costs section. The Award Fee annual percentage is $1.4 \%$ in Year $1,1.4 \%$ in year 2 , and $1.3 \%$ in subsequent fiscal years. 


\section{Dr. Roderick A. Hyde}

PRESENT POSITION:

Laser Science \& Technology Program

Lawrence Livermore National Laboratory

L-477, 7000 East Avenue, Livermore, CA. 94550

(925) 4227289 hydel@llnl.gov

\section{EDUCATION:}

9/73 - 6/76, Massachusetts Institute of Technology, Cambridge, MA, Ph.D. (Aeronautics and Astronautics)

9/72 - 6/73, Massachusetts Institute of Technology, Cambridge, MA, M.S. (Aeronautics and Astronautics)

9/70 - 6/72, Massachusetts Institute of Technology, Cambridge, MA, B.S. (Aeronautics and Astronautics)

\section{PREVIOUS RESEARCH EXPERIENCE:}

Design of advanced space transport: laser fusion rockets, dynamic skyhooks, small-payload boosters

Space-based directed energy weapons

Ballistic missile defense

\section{HONORS:}

Fannie \& John Hertz Foundation Fellowship 1972-1976

DOE Military Applications Award of Excellence, 1986

R\&D 100 Award, 1991

\section{PUBLICATIONS:}

"Design and Behavior of Ribless Solar Reflectors," Roderick A. Hyde, Ph.D. Thesis, UCRL-52191 (LLNL 1976).

"A Laser Fusion Rocket for Interplanetary Propulsion", Roderick A. Hyde, LAF-83-396, (LLNL 1983).

"Earthbreak: A Review of Earth-to-Space Transportation", Roderick A. Hyde, Energy in Physics, War and Peace, pp 283-307, (Kluwer Academic Publishers, 1988).

"Large Aperture Fresnel Telescopes", Roderick A. Hyde, UCRL-ID-131320 (July 1998)

'Eyeglass: 1. Very Large Aperture Diffractive Telescopes", Applied Optics, Vol. 38, p 4198, 1999 


\section{Celeste M. Satter}

Ms. Satter is currently a Senior Member of Technical Staff in the Mission and Systems Architecture Section, Jet Propulsion Laboratory, California Institute of Technology

EXPERTISE: Integrated System Architecture Development and Multidisciplinary Analysis for Technology Assessment and Performance Evaluation of Advanced Space Systems;

Particular Expertise in Precision RF and Optical Systems

\section{HIGHLIGHTS OF QUALIFICATIONS}

$>$ Diverse spacecraft systems design and multidisciplinary simulation experience on a wide range of advanced NASA and DOD projects

$>$ Twenty years experience in technology assessment and development for precision and deployable spacecraft structures

$>$ Successful proposal development and task leadership ability

\section{Svstems Design \& Engineering --}

\section{PROFESSIONAL EXPERIENCE}

- Developed a multi-disciplinary spacecraft system design model for evaluation of advanced technologies and endto-end system design optimization of a Neptine orbiter mission

- Developed integrated inflatable structures design, performance assessment, and costing tools for use in rapid turnaround advanced concept studies and proposal efforts

- Generated an integrated system design model of a microspacecraft propulsion stage and used this model to evaluate key technologies and determine minimum achievable stage mass

- Served as Systems Engineering lead for Team X: JPL's advanced flight projects concurrent engineering team

Technology Assessment \& Development -

- Generated conceptual designs and technology development plans for innovative lightweight deployable structures for synthetic aperture radars

- Determined user requirements and established long-range technology development plans for inflatable deployable spacecraft structures for NASA, DOD, and commercial applications

- Surveyed and evaluated industry capability and assessed technology readiness for deep space optical communications and commercial mobile (RF) satellite communications antennas

- Recently co-led an effort to define a roadmap for NASA's future nanotube technology development

Design, Modeling, and Analysis of Precision Structures und Instruments -

- Performed conceptual design, developed finite-element and other software models, and evaluated analytical performance of a wide range of precision $\mathrm{RF}$ and optical systems including interferometers, infrared telescopes, space-based radars, space-based lasers, radioastronomy and astrophysics telescopes, spacecraft communications systems, and earth observation (synthetic aperture radar) instruments

- Led a multidisciplinary team in the development of an integrated physics-based simulation of a microspacecraft asteroid-flyby mission

\section{EMPLOYMENT HISTORY}

JET PROPULSION LABORATORY, Pasadena, CA Senior Engineering Staff 1987-Present SPACE SYSTEMS ANALYSIS, Watervliet, NY CAMBRDGE RESEARCH ASSOC., Cambridge, MA C. S. DRAPER LABORATORY, Cambridge, MA Engineering Consultant

\section{EDUCATION}

M.S. Space Systems Engineering, Department of Aeronautics and Astronautics, Massachusetts Institute of Technology -- 1980; B.S. Aeronautics and Astronautics, Massachusetts Institute of Technology -- 1978 


\title{
Robert P. Hoyt, Ph.D.
}

\author{
1917 NE 143rd St, Seattle, WA 98125-3236 \\ Home: (206) 362-3088 Work: (206) 306-0400 Fax: (206) 306-0537 \\ email: hovt@tethers.com
}

SUMMARY Aerospace engineer with experience combining experimental research and numerical simulation to develop innovative solutions to problems in space propulsion, space structures, plasma physics, plasma-based material processing, and commercial applications of space technology.

SKILLS - Management: Principal investigator on 5 NASA Small Business Innovation Research and NASA Institute for Advanced Concepts contracts. Led a distributed team of employees, hardware vendors, and consultants in the design of a satellite component.

- Experimental: Experienced with experimental techniques including plasma probes, infrared imaging calorimetry, IR \& FIR lasers and detectors, and plasma-based manufacturing. Entrepreneurial development of low-cost space hardware.

- Numerical: Development and use of CFD and finite element simulation software to model plasmas, space structures, radiation transfer, and material processing physics. Experience with the MACH2 plasma code.

- Computer: $12+$ years experience programming $\mathrm{C}^{++}$on Mac, UNIX, and DOS environments. Also experienced with FORTRAN, Pascal, and HTML. Proficient with a wide range of software packages, including IDL, MatLab, AutoCad, LabView, Illustrator, PageMaker, and CodeWarrior.

- Communications: Authored 9 journal articles, 26 technical publications, and numerous contract reports. These publications have consistently received praise from reviewers and colleagues for quality of writing and presentation clarity. Authored five successful NASA SBIR and NIAC proposals.

\section{EMPLOYMENT}

July '97- present

Dec. '94-June' 97

June '92-Sept. '94

Jan. -June' ' 92

Sept. ' $90-$ June ' 92

1989-1990
President, CEO, and Chief Engineer, Tethers Unlimited, Inc., Clinton WA.

Partner and Chief Engineer, Tethers Unlimited, Clinton, WA.

Graduate Research Assistant, Los Alamos National Laboratory, Los Alamos, NM.

Space Technology Consultant, Forward Unlimited, Seattle, WA.

Research Assistant, University of Washington, Seattle, WA.

Research Assistant, Physics Department, Williams College, Williamstown, MA.

EDUCATION University of Washington, Dept. of Aeronautics and Astronautics, Seattle, WA.

Ph.D. Dec. 1994.

Dissertation: Optimization of Magnetic Nozzles for Coaxial Plasma Accelerators

Williams College, Williamstown, MA.

BA with Highest Honors in Physics, 1990.

Magna Cum Laude, Phi Beta Kappa, Sigma Xi.

Relevant Publications

- Hoyt, R.P. and Uphoff, C.W., "Cislunar Tether Transport System," J. Spacecraft and Rockets, 37(2) MarchApril 2000, pp. 177-186.

- Forward, R.L., Hoyt, R.P., "Space Tethers," Scientific American, February 1999, pp. 86-87.

- Forward, R.L and Hoyt, R.P., "Electrodynamic Tether and Method of Use," U.S. Patent number 6,116,544, awarded 12 Sept 2000.

- Forward, R.L and Hoyt, R.P., "Failure Resistant Multiline Tether," Patent application PCT/US97/05840, filed 22 April 1997.

- Hoyt, R.P., et al., "Design and Simulation of a LEO to GTO Tether Boost Facility," AIAA Paper 2000-3866, $36^{\text {th }}$ Joint Propulsion Conference, Huntsville, AL, July 17-19, 2000.

- Hoyt, R.P., Forward, R.L., "Failsafe Multistrand Tether SEDS Technology," 4th International Conference on Tethers in Space, Washington, DC, April 1995. 


\section{Dr. James T. Early}

3375 Edinburgh Drive, Livermore, CA 94550

Work Phone (925) 422-6221, early2@1lnl.gov

\section{Education}

1973 Stanford University, Ph.D., Aeronautics \& Astronautics (physics minor)

1965 California Institute of Technology, M.S., Mechanical Engineering (propulsion)

1964 M.I.T., B.S., Aeronautics \& Astronautics

\section{Professional Experience}

June 1999 to Present, Deputy Assistant Program Leader, Short Pulse Laser Applications \& Technology, Lawrence Livermore National Laboratory (LLNL)

Technologies in this group involve the use of very short pulse lasers $(0.4-10$ picosecond) for laser machining, physics and other applications. Diffractive optics fabrication technology developed for these lasers is now being expanded for applications to very large space based telescopes. The group's projects emphasize engineering scaling of advance laser and optics concepts.

November 1974 to June 1999, Program Manager, Systems Analysis Manager, Extractor Group Leader and Staff to Program Manager, Atomic Vapor Laser Isotope Separation Program, LLNL

As Program Manager, I managed a rapid expansion and transition of AVLIS from a $\$ 35 \mathrm{M} / \mathrm{y}$ development and demonstration program to a $\$ 165 \mathrm{M} / \mathrm{y}$ program aimed towards industrial deployment. I have been involved in specific technology projects in almost all the various AVLIS subsystems. The primary emphasis was on economic and strategic planning, fluid and thermal analysis, modeling of complex systems, and chemical and discharge kinetics. I also served at various times on the Laser Directorate Strategic Planning Group, the LLNL Strategic Planning Group, the LLNL Energy Review Group and the DOE Uranium Enrichment Strategic Planning Group. 1990: Served on DOE-NASA-DOD Synthesis Group to evaluate the future focus of space exploration and to identify opportunities for interagency cooperative programs

February 1973 to October 1974, Laser Kinetics Group Leader, Hughes Aircraft Company, Culver City, CA I worked on plasma physics problems in electron beam ionized, flowing, atmospheric pressure $\mathrm{CO}_{2}$ lasers.

June 1967 to March 1969, Senior Research Scientist, Lockheed Missiles and Space Company, Sunnyvale, CA I worked on problems of compressible, reacting gases for external and internal flows for missiles.

June 1965 to September 1966, Propulsion Engineer, Donnell-Douglas Aircraft Company, Culver City, CA I worked on the propulsion system of the Delta launch vehicle.

Summers of 1961, 1962, 1963 and 1964, NASA, Goddard SFC, Greenbelt, MD

I worked on the performance and trajectory analysis of the Delta launch vehicle

\section{Space Related Pupers}

1) Early,J.T., "Requirements-Driven Designs For Human Expansion Into The Galaxy", to be published in J.British Interplanetary Society(IBIS)

2) Early, J.T. and London, R., "Dust Grain Damage To Interstellar Laser-Pushed Lightsail", NASA $10^{\text {th }}$ Advanced Propulsion Workshop (April 1999) and J.of Spacecraft and Rockets, vol.37, no.4, p526-532, July 2000

3) Early, J.T., "Space-Based Solar Shield to Offset Greenhouse Effect", JBIS, vol.42, pp567-9, 1989.

4) Early, J.T., "Space Transportation Systems with Energy Transfer and Force Beams", JBIS, vol.40, p371-2, 1987.

AVLIS Patents and Papers: Approximately eight patents and thirty internal papers (mostly classified) on various aspects of AVLIS project with the focus being on uranium vaporizer system. 


\section{Dr. Shamasundar Dixit}

PRESENT POSITION:

Laser Science \& Technology Program

Lawrence Livermore National Laboratory

L-477, 7000 East Avenue, Livermore, CA. 94550

(925) 4237321 dixit1@llnl.gov

EDUCATION:

1/80 Ph. D. Physics University of Southern California, Los Angeles, CA

6/76 A. M. Physics, University of Southern California, Los Angeles

6/74 B. Sc Physics University of Bombay, Bombay India

PREVIOUS RESEARCH EXPERIENCE:

Design and fabrication of large aperture diffractive optics for high-power lasers

Studies of intense field laser matter interaction phenomena, multiphoton processes

Non-linear optics of organic conducting polymers

HONORS:

"Outstanding Program Accomplishment" Award, P\&ST Directorate, 1995

PUBLICATIONS:

S. N. Dixit, I. M. Thomas, B. W. Woods, M. A. Henesian, P. J. Wegner and H. T. Powell, "Large Aperture Sol-gel Random Phase Plates for Beam Smoothing on the Nova Laser," Applied Optics. 322543 (1993) and also in ICF Quarterly Report, Lawrence Livermore National Laboratory, 390 (1993) [UCRL-LR-105821-93-2].

S. N. Dixit, J. K. Lawson, K. R. Manes, H. T. Powell and K. A. Nugent, "Kinoform phase plates for focal plane irradiance profile control," Optics Letters 19417 (1994).

S. N. Dixit, M. D. Feit, M. D. Perry and H. T. Powell, "Designing fully continuous phase screens for tailoring focal plane irradiance profiles," Opt. Lett. 211715 (1996).

M. C. Rushford, S. N. Dixit, I. M. Thomas, A. M. Martin and M. D. Perry, "Large aperture kinoform phase plates in fused silica for spatial beam smoothing on Nova and the Beamlet lasers," to be published in the proceedings of 2nd Annual International Conference on Solid-state Lasers for Inertial Confinement Fusion, Paris, France (1996).

S. N. Dixit, M. C. Rushford, I. M. Thomas, S. M. Herman, J. A. Britten, B. W. Shore and M. D. Perry, "Color separation gratings for diverting the unconverted light away from the NIF target," to be published in the proceedings of 2nd Annual International Conference on Solid-state Lasers for Inertial Confinement Fusion, Paris, France (1996).

J. E. Rothenberg, J. M. Auerbach, S. N. Dixit, S. W. Haan, S. M. Pollaine and W. H. Williams, "Focal spot conditioning for indirect drive on the NIF," Supplement to SPIE Vol 3492 pp 65-77 (1998). 


\section{Dr. Andrew H. Weisberg}

PRESENT POSITION:

Physics and Applied Technology Directorate

Lawrence Livermore National Laboratory

L-174, 7000 East Avenue, Livermore, CA 94550

(925) 422-7293 weisberg1@)lnl.gov

EDUCATION:

9/86-6/91, Stanford University, Stanford, CA, PhD (Electrical Engineering: Laser Planarization of Multilayer Interconnects [with contributions in Materials Science, Computer Science, Thermodynamics])

9/85-6/86, Stanford University, Stanford, CA, Engineer (Aeronautics and Astronautics: Water Walking Robots for Ocean Surface Applications [Robotics, Control Theory])

9/77-6/79, Stanford University, Stanford, CA, M.S. (Applied Physics)

9/75-6/77, Stanford University, Stanford, CA, M.S. (Electrical Engineering)

9/71-6/75, Massachusetts Institute of Technology, 3 simultaneous B.S. (Mechanical Engineering, Electrical Engineering, Aeronautics and Astronautics, also Physics core courses)

PREVIOUS RESEARCH EXPERIENCE:

Experimental Breakthroughs in :

Classified UAV's

Robot Vehicles - 'Robochicken' held limbed locomotion speed records for 15 years

Rocketry - Founder (1 of 10) of first privately-funded launch vehicle development venture (Amrock)

Vehicle Control Systems with Real-Time Multiprocessing - very advanced for 1978

Microfabrication (2 nanosecond response time RTD's), Laser Optics, Transient Processing of Thin Films,

Materials Science - first to identify uncertain $C p(T), \kappa(T)$ to $2500^{\circ} \mathrm{C}$ from RTD's $p(t)$

$\mathrm{CAE}-\mathrm{ME} / \mathrm{A}+\mathrm{A} / \mathrm{Chemistry}$ design tools for integrated miniature propulsion $\mathrm{R}+\mathrm{D}$

Theoretical innovations include :

Scientific Method - computer disproof of hypothetical physical mechanisms

Characteristic equations - total solution for viscous, finite-depth capillary waves

HONORS:

Fannie \& John Hertz Foundation Fellowship 1975-1979

PUBLICATIONS:

P.H. Carter II, F. Mitlitsky, A.H. Weisberg, J.C. Whitehead, and R.W. Humble. 1999, "Design Trade Space for a Mars Ascent Vehicle for a Mars Sample Return Mission," Acta Astronautica, 45 (4-9), 31 1-318; UCRL-JC-130277

F. Mitlitsky, A.H. Weisberg, P.H. Carter, B. Myers, and J.T. Kare. 2000, "Applications of Water Refuelable Spacecraft," Final Report to DARPA/TTO, Agreement \#99-G527, January 5, 2000; UCRL-ID-137296

F. Mitlitsky, A.H. Weisberg, B. Myers, et al. 1999-a, "Water rocket - Electrolysis Propulsion and Fuel Cell Power," AIAA-99-4609, AIAA Space Technology Conference, Albuquerque, NM, September 28-30 (1999); UCRL-JC135315

D. Tuckerman and A.H. Weisberg, "Laser Planarization", IEEE J. Circuits and Systems (1987)

H. W. Chin, W. C. Newman, A.H. Weisberg, et. al, "Water-Walking Robots for Naval Surface Applications", Final Report to Navy Material Command, (UCID 1979) 
Folded Optical Lens Deployment (FOLD) Demonstration

Of a 1.5 - 2.4 meter Lightweight Diffractive Optic

\section{Dr. Michael Shao}

Address: Jet Propulsion Lab, 301-470

4800 Oak Grove, Pasadena, Calif. 91109

818-354-7834 Tel, 818-393-9471 Fax, e-mail: mshao@huey.jpl.nasa.gov

Education: Massachusetts Institute of Technology, B.S., 1971

Massachusetts Institute of Technology, Ph.D., 1978

Specialized Experience:

Ultra precise linear/angular metrology (picometer, picoradian)

Optical synthetic aperture imaging

Freq stabilized lasers, electro-optics

Present Manager, Interferometry Center

1996-present SIM (Space Interferometry Mission) Project Scientist

Keck Interferometer Project Scientist

1989-1996 Supervisor, Spatial Interferometry Group JPL. Research in stellar interferometry

1984-1989 Astrophysicist, Smithsonian Astrophysical Observ., Research in Stellar Interferometery

1981-1984 Astrophysicist, Navel Research'Laboratory, Research in Stellar Interferometry

1978 -1981 Posdoctoral Associate, MIT, Research in Interferometer Astrometry

American Astronomical Society, Member;

Optical Society of America, Fellow

Abbreviated Publication List

"The Visual Orbit of 64 Piscum"; A.F. Boden, B.F. Lane, M.J. Creech-Eakman, M.M. Colavita, P.J. Dumont, J. Gubler, C.D. Koresko, M.J. Kuchner, S.R. Kulkarni, D.W. Mobley, X.P. Pan, M. Shao, G.T. van Belle, J.K. Wallace, B.R. Oppenheimer, 1999, ApJ 527, 360.

"The Visual Orbit of Iota Pegasi"; A.F. Boden, C.D. Koresko, G.T. van Belle, M.M. Colavita, P.J. Dumont, J. Gubler, S.R. Kulkarni, B.F. Lane, D. Mobley, M. Shao, J.K. Wallace, 1999, ApJ 515, 356.

"The Palomar Testbed Interferometer"; M.M. Colavita, J.K. Wallace, B.E. Hines, Y. Gursel, F. Malbet, D.L. Palmer, X.P. Pan, M. Shao, J.W. Yu, A.F. Boden, P.J. Dumont, J. Gubler, C.D. Koresko, S.R. Kulkarni, B.F. Lane, D.W. Mobley, G.T. van Belle, 1999, ApJ, 510, 505-521

"The Visual Orbit of the 0.002" RS CVn Binary Star TZ Triangulum from Near-Infrared Long-Baseline Interferometry"; C. D. Koresko, G.T. van Belle, A.F. Boden, M.M. Colavita, M.J. Creech-Eakman, P.J, Dumont, J. Gubler, S.R. Kulkarni, B.F. Lane, D.W. Mobley, X.P. Pan, M. Shao, J.K. Wallace, 1998, ApJL, 509, L45-L48.

"A Protoplanetary disk around FU Orionis Resolved by Infrared Long-Baseline Interferometry"; F. Malbet, J.-P.Berger, M.M. Colavita, M. Shao, J.K. Wallace, A.F. Boden, G.T. van Belle, D.W. Mobley, C. Beichman, C.D. Koresko, S.R. Kulkarni, B.F. Lane, X.P. Pan, 1998 ApJL, 507, L149-L152.

"An Interferometric Search for Bright Companions to 51 Pegasi"; A.F. Boden, G.T. van Belle, M.M. Colavita, P.J. Dumont, J. Gubler, C.D. Koresko, S.R. Kulkarni, B.F. Lane, D.W. Mobley, M. Shao, J.K. Wallace, 1998, ApJL, 504, L39.

"Visibility Calibrations With the Palomar Testbed Interferometer"; A.F. Boden, M.M. Colavita, G.T. van Belle, M. Shao, 1998, Proc SPIE, 3350-40, 872 
Folded Optical Lens Deployment (FOLD) Demonstration Of a 1.5 - 2.4 meter Lightweight Diffractive Optic

\section{Dr. Richard L. Baron}

\section{Oak Grove Drive, M/S: 306-388, Pasadena, CA 91109-8099 \\ 818-354-8677 rlb@huey.jpl.nasa.gov}

Education Ph.D., Massachusetts Institute of Technology, August 1989.

Dept of Earth, Atmospheric and Planetary Sciences

Experience:

May97-present Jet Propulsion Laboratory, Senior member technical staff.

As an alternate Technology Community Leader, worked with the Chief Technologist to develop Roadmaps for future growth and funding sources within the area of Interferometry.

Managed Enhanced Components tasks within SIM ITP. Developed an athermalized beam launcher, and highly accurate corner cubes; lam/1000 surfaces, knife edges, Ion assisted Gold.

1990-May97 NASA Infrared Telescope Facility, U. of Hawaii, Associate Astronomer- Planetary

Project Scientist/Manager (3 meter IRTF telescope) responsible for design, development and implementation of computer controlled active optics (image stabilization) hardware linked to the internet The system consisted of a fast CCD imaging system controlling a high performance tip-tilt secondary on the 3 meter telescope located on Mauna Kea (13,700 feet altitude).

Managed $\sim 2 \mathrm{M}$ effort to reduce the dome and telescope seeing at the IRTF $3 \mathrm{~m}$.

Discovered IO Flux Tube foot illumination in Jupiter's Ionosphere. Also first to globally image the Jovian Aurorae and demonstrate solar wind modulation.

1984-1990 M.I.T. Earth Atmospheric and Planetary Sciences Dept. Research Eng, Grad St. Developed and managed the M.I.T. astronomy telescience program while a graduate student. This allowed remote operation of an observatory $\sim 30$ miles from the campus.

Determined Saturn's upper atmosphere temperature-density profile from photometric stellar occultation measurements.

Determined the Oblateness of Uranus at the 1 micro-bar Level from legacy stellar occultation data.

Honors Awarded National Research Council Fellowship (1989)

Southern Scholarship and Research Foundation scholar as an undergraduate

\section{Recent Publications and presentations}

1999 "The Practice of Interferometry in Space with the Space Interferometry Mission Instrument", M. Shao, R. Baron, Working on the Fringe: OPTICAL AND IR INTERFEROMTRY FROM GROUND AND SPACE, Astronomical Society of the Pacific Conference Series Vol 194, 1999

"SIM vs. SOS: A Space Interferometry Trade Study", R. Baron , M. Milman, K. Aaron Kona SPIE Conference on Interferometry 1997.

"SIM Configuration Trades," Kim M. Aaron, William H. Mateer II, Richard L. Baron

Kona SPIE Conference on Interferometry 1997.

20 additional publications and presentation 1992-1996 
University of California

Lawrence Livermore National Laboratory

Technical Information Department

Livermore; CA 94551

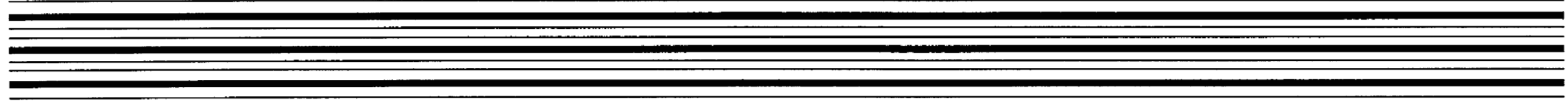

